\title{
Tumor- and mitochondria-targeted nanoparticles eradicate drug resistant lung cancer through mitochondrial pathway of apoptosis
}

He Wang ${ }^{1,2 \dagger}$, Fangke Zhang ${ }^{1 \dagger}$, Huaying Wen ${ }^{1}$, Wenwen Shi ${ }^{1}$, Qiudi Huang ${ }^{1}$, Yugang Huang ${ }^{1}$, Jiacui Xie ${ }^{1}$, Peiyin $\mathrm{Li}^{1}$, Jianhai Chen ${ }^{4}$, Linghao $\mathrm{Qin}^{3^{*}}$ and Yi Zhou ${ }^{{ }^{*}}$ (1)

\begin{abstract}
Chemotherapeutic drugs frequently encounter multidrug resistance. ATP from mitochondria helps overexpression of drug efflux pumps to induce multidrug resistance, so mitochondrial delivery as a means of "repurposing" chemotherapeutic drugs currently used in the clinic appears to be a worthwhile strategy to pursue for the development of new anti-drug-resistant cancer agents. TPP-Pluronic F127-hyaluronic acid (HA) (TPH), with a mitochondria-targeting triphenylphosphine (TPP) head group, was first synthesized through ester bond formation. Paclitaxel (PTX)-loaded TPH (TPH/PTX) nanomicelles exhibited excellent physical properties and significantly inhibited A549/ADR cells. After TPH/ PTX nanomicelles entered acidic lysosomes through macropinocytosis, the positively charged TP/PTX nanomicelles that resulted from degradation of HA by hyaluronidase (HAase) in acidic lysosomes were exposed and completed lysosomal escape at $12 \mathrm{~h}$, finally localizing to mitochondria over a period of $24 \mathrm{~h}$ in A549/ADR cells. Subsequently, TPH/PTX caused mitochondrial outer membrane permeabilization (MOMP) by inhibiting antiapoptotic Bcl-2, leading to cytochrome $C$ release and activation of caspase-3 and caspase-9. In an A549/ADR xenograft tumor model and a drug-resistant breast cancer-bearing mouse model with lung metastasis, TPH/PTX nanomicelles exhibited obvious tumor targeting and significant antitumor efficacy. This work presents the potential of a single, nontoxic nanoparticle (NP) platform for mitochondria-targeted delivery of therapeutics for diverse drug-resistant cancers.
\end{abstract}

Keywords: Mitochondrial targeting, Paclitaxel, Nanomicelles, Multidrug resistance, Cancer therapy

\section{Introduction}

Lung cancer is the leading cause of cancer-related mortality worldwide [1]. Despite recent advances in treatment, lung cancer remains an incurable disease [2]. Paclitaxel

*Correspondence: zhouyi0264@126.com; qins_lab@163.com ${ }^{\dagger} \mathrm{He}$ Wang and Fangke Zhang contributed equally to this work ${ }^{1}$ Key Laboratory of Molecular Clinical Pharmacology \& Fifth Affiliated Hospital, Guangzhou Medical University, Guangzhou 511436, Guangdong, China

${ }^{3}$ School of Pharmacy, Guangdong Pharmaceutical University, Guangzhou 510006, Guangdong, China

Full list of author information is available at the end of the article
(PTX), which is a natural plant product extracted from the bark of western yew (Taxus brevifolia), has commonly been used as a promising front-line agent for the treatment of lung cancer and exhibits activity against a broad range of cancers mainly by acting on the mitochondria [3-5] and microtubules of cancer cells [6]. However, the anticancer activity of PTX is significantly limited due to its poor aqueous solubility [7]. Taxol is a pharmaceutical formulation of PTX and is used in the clinical treatment of cancers. However, Taxol causes a severe hypersensitivity reaction due to the solvent Cremophor EL in its formulation [6]. However, multidrug resistance, whether

c) The Author(s) 2020. This article is licensed under a Creative Commons Attribution 4.0 International License, which permits use, sharing, adaptation, distribution and reproduction in any medium or format, as long as you give appropriate credit to the original author(s) and the source, provide a link to the Creative Commons licence, and indicate if changes were made. The images or other third party material in this article are included in the article's Creative Commons licence, unless indicated otherwise in a credit line to the material. If material is not included in the article's Creative Commons licence and your intended use is not permitted by statutory regulation or exceeds the permitted use, you will need to obtain permission directly from the copyright holder. To view a copy of this licence, visit http://creativeco mmons.org/licenses/by/4.0/. The Creative Commons Public Domain Dedication waiver (http://creativecommons.org/publicdomain/ zero/1.0/) applies to the data made available in this article, unless otherwise stated in a credit line to the data. 
inherent or acquired, has dramatically compromised the effectiveness of drug efflux pumps toward PTX [8].

Although chemotherapy plays a primary role in the management of cancers, the efficacy of chemotherapy seems to be decreased by the multidrug resistance of cancers. Mitochondria are the powerhouses of the cell and serve as attractive targets for cancer treatment. Multidrug-resistant (MDR) cancer cells exhibit increased mitochondrial mass with more polarized mitochondria than non-MDR cells [9]. As multidrug resistance arises due to the overexpression of drug efflux pumps, which require ATP from mitochondria, mitochondrial targeting is a particularly sensible option for the treatment of drug-resistant cancer cells $[10,11]$. Thus, in MDR cancer cells, the highly polarized mitochondrial membranes are important targets and are associated with ATP-dependent drug efflux.

Delocalized lipophilic cations play a key role in mitochondrial targeting [12], accumulating to a greater degree in the mitochondria of cancer cells than in those of normal cells due to the high negative mitochondrial membrane potentials of cancer cells [13]. Triphenylphosphonium (TPP) is frequently used in delocalized lipophilic cations, which usually decorate the surfaces of nanoparticles (NPs) or are covalently linked to nanocarriers for mitochondrial targeting [13]. Furthermore, good treatment results were acquired. However, single targeting of mitochondria is difficult to deal with the increasing drug resistance of tumor [14].

In order to further play a role which TPP targeted mitochondrial, PF127 (FDA approved, poly(ethylene oxide)-block-poly(propylene oxide)-block-poly(ethylene oxide), PEO-PPO-PEO triblock copolymer) was applied into modify TPP, has been widely used as a pharmaceutical adjuvant. Moreover, this polymer can interact with cell membranes, leading to decreased microviscosity, pore formation on the membrane and accelerated "flipflop" of the membrane component, increasing the reversion of drug resistance. However, PF127, with a high hydrophile-lipophile balance (HLB) value, exhibits poor cellular membrane binding [15]. It is hypothesized that the conjugation of TPP with PF127 (TPP-PF127, TP) could decrease the HLB value. Thus, TP would be easily internalized into tumor cells.

To neutralize the positive charges of TP nanomicelles, to avoid quick clearance and to achieve longterm circulation, negatively charged hyaluronic acid (HA) was further grafted with OH-PF127-TPP through covalent bonds due to the hydrophilic and negatively charged outer shell [16]. Simultaneously, specific tumor-targeting nanomicelles were found between TPP-PF127-HA (TPH) and CD44 receptors overexpressed on tumor cells. As illustrated in Scheme 1,
PTX-loaded TPH NPs will target tumor cells through ligand-receptor interactions. The HA molecules could be degraded by hyaluronidase (HAase), which is highly abundant in the tumor extracellular matrix and lysosomes. The lysosome escape of nanomicelles depends on the positive charges and proton sponge effect of the quaternary ammonium groups of TP nanomicelles [17]. Finally, positively charged TP/PTX nanomicelles accumulate in negatively charged mitochondria and induce MDR cancer cell apoptosis by activating intrinsic mitochondrial apoptosis pathways.

\section{Methods}

\section{Materials and general characterization}

Pluronic F127 $(\mathrm{Mw}=12,600)$ was purchased from BASF aktiengesellschaft, and (5-carboxypentyl)triphenylphosphonium bromide (TPP-COOH) was purchased from Bailingwei Co., Ltd., Guangzhou, China. HA and HAase were acquired from J\&K Scientific Ltd. (Beijing, China). $N, N^{\prime}$-dicyclohexylcarbodiimide (DCC), 4-dimethylaminopyridine (DMAP), genistein, chlorpromazine, amiloride, coumarine-6 (C6), and PTX were purchased from Sigma-Aldrich (Shanghai, China). Fetal bovine serum (FBS) and RPMI 1640 medium were purchased from HyClone and Gibco, respectively (Thermo Fisher Scientific Co., Ltd., Shanghai, China). The near-infrared (NIR) fluorescent dye DIR was supplied by Keygen Biotech (KGMP0026, China). Hematoxylin and eosin (H\&E) staining reagents were supplied by Leagene Biology Technology Co., Ltd. (Beijing, China). MitoTracker Red and LysoTracker ${ }^{\circledR}$ Red were purchased from Yeasen Biotech Co., Ltd. (Shanghai, China). All other reagents were of analytical grade.

\section{Synthesis of TPP-PF127-HA}

\section{Synthesis of the PF127-TPP copolymer}

The TPP-PF127 (TP) conjugate was synthesized by the procedures reported by Kun $\mathrm{Na}[18,19]$. Briefly, PF127 powder (100 mg, $1 \mathrm{mmol}$ ) was dissolved in anhydrous DMSO. COOH-TPP (9.1 mg, $2.5 \mathrm{mmol})$, DCC $(1.5 \mathrm{mmol})$, and DMAP $(1.5 \mathrm{mmol})$ were dissolved in DMSO $(5 \mathrm{~mL})$. The reaction mixture was stirred at room temperature using a magnetic stirrer and allowed to react under nitrogen for $24 \mathrm{~h}$, followed by dialysis (Mw cutoff: $1000 \mathrm{Da}$ ) for 3 days against distilled water to remove unconjugated COOH-TPP and DMSO. The final solution was flash-frozen dry and lyophilized.

\section{Synthesis of the TPP-PF127-HA copolymer}

$\mathrm{HA}$ and TP were dissolved in DMSO (3 mL) in a molar ratio of 2:1 with large amounts of DCC and DMAP. The reaction mixture was stirred at room temperature using a 


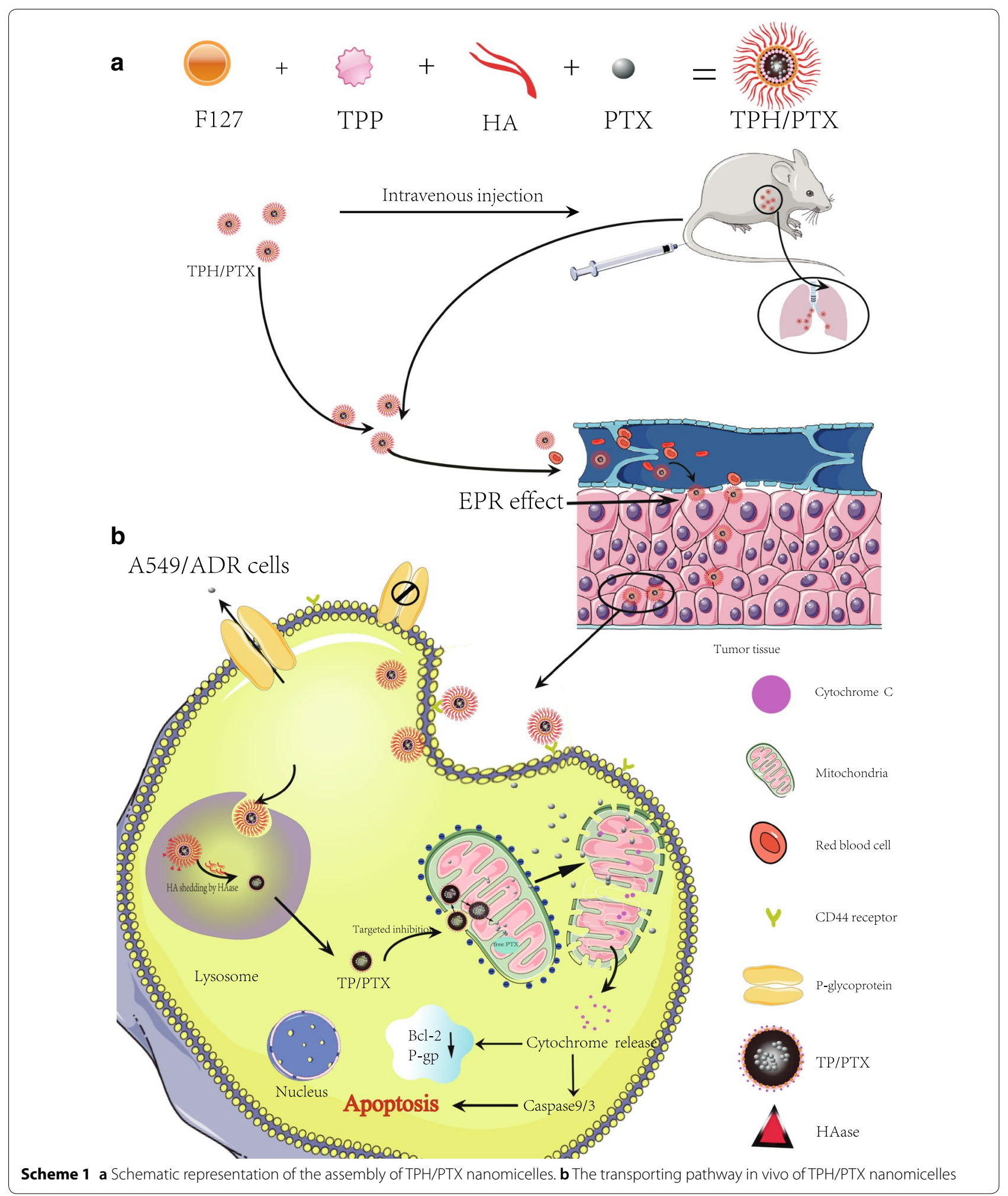


magnetic stirrer and allowed to react under closed conditions for $24 \mathrm{~h}$. The filtrate was dialyzed for $24 \mathrm{~h}$ (Mw cutoff: 10,000 Da) and dried under reduced pressure.

\section{Preparation of PTX-loaded TPP-PF127-HA (TPH/PTX) nanomicelles}

PTX-loaded nanomicelles were prepared using a nanoprecipitation method. Briefly, nanoprecipitation involved the dissolution of TPH in water to form an aqueous phase, while PTX was dissolved in an organic solvent such as acetone or ethanol to form an oil phase. Then, the oil phase was injected into the water phase under stirring; stirring was continued; and the organic solvent was evaporated. Finally, the drug-loaded micelles were obtained, and the spherical or spheroidal micelles were observed by transmission electron microscopy (TEM). TP/PTX was prepared using the same procedure. The particle size and zeta potential of the NPs were characterized using a Malvern Zetasizer Nano ZS90. In vitro TPH/PTX drug release was measured by HPLC (Waters Corp., Waltham, MA, USA). The prepared TPH/PTX nanomicelles were suspended in phosphate-buffered saline (PBS, $0.02 \mathrm{M}, \mathrm{pH}$ 7.4) containing PTX at a concentration of $50 \mu \mathrm{g} / \mathrm{mL}$. After the solution $(1 \mathrm{~mL})$ was transferred to dialysis tubing, $0.2 \%$ Tween PBS $(30 \mathrm{~mL})$ was added to immerse the tubing. At predetermined intervals, the external buffer was collected, and an equivalent volume of fresh buffer was added. The concentration of PTX in the collected solution was determined by HPLC analysis [20]. The drug loading capacity (DLC) and drug loading efficiency (DLE) were calculated according to the following formulas:

$$
\begin{aligned}
\operatorname{DLC}(\%)= & \text { weight of drug used } / \\
& (\text { weight of polymer }+ \text { drug used }) \times 100 \% \\
\operatorname{DLE}(\%)= & \text { weight of loaded drug/ } \\
& \text { weight of input drug } \times 100 \%
\end{aligned}
$$

\section{Stability}

The stability of the TPH in different conditions was examined using the protocol described in reference [21].

\section{Cell culture}

Human lung adenocarcinoma A549 cells, drug-resistant A549 cells overexpressing P-gp (A549/ADR), and drug-resistant mouse breast cancer 4T1 (4T1/ADR) cells (College of Pharmaceutical Science, Guangzhou Medical University, Guangzhou, China) were grown in
RPMI-1640 supplemented with 10\% FBS and 1\% antibiotics $(100 \mathrm{U} / \mathrm{mL}$ penicillin and $100 \mathrm{mg} / \mathrm{mL}$ streptomycin). For maintenance of drug resistance, A549/ $\mathrm{ADR}$ and $4 \mathrm{~T} 1 / \mathrm{ADR}$ cells were cultured in the presence of $4 \mu \mathrm{M}$ CDDP, and CDDP-free medium was used for 1 week prior to initiation of the experiments [20]. Cell cultivation was performed in a humidified incubator maintained at $37^{\circ} \mathrm{C}$ containing $5 \% \mathrm{CO}_{2}$. All of the cell studies were approved by the Institutional Animal Care Committee and the Local Veterinary Office and Ethics Committee at Guangzhou Medical University (GZMUC 10-05010).

\section{Cytotoxicity and hemo-compatibility of nanomicells}

A549 cells or A549/ADR cells were incubated with fresh culture media containing varying concentrations of TP, TPH, Taxol, TP/PTX, and TPH/PTX nanomicelles at $37^{\circ} \mathrm{C}$ for $1 \mathrm{~h}$. The final concentration of PTX was approximately $0-50 \mu \mathrm{M}$, and the concentration of the blank nanomicelles was consistent with that of the PTX-loaded nanomicelles. Blank culture medium was used as the blank control. After $24 \mathrm{~h}, 48 \mathrm{~h}$, and $72 \mathrm{~h}$ of incubation, cell viability was measured by proliferation assays [3], with each assay performed in triplicate. Finally, doseeffect curves were created, and the drug concentration that inhibited $50 \%$ of cell growth (IC 50) was calculated by curve fitting the cell viability data to that of the control samples.

Hemo-compatibility of nanomicelles is examined using the protocol described in reference [22].

\section{Apoptosis-inducing effect}

Apoptosis rates were measured using the FITC Annexin V-staining Kit and a FACScan flow cytometer (BD, USA). A549 and A549/ADR cells were seeded in six-well plates $\left(5 \times 10^{5}\right.$ cells/well). After incubation for $24 \mathrm{~h}$, the medium was replaced with RPMI 1640 supplemented with the above formulations with $10 \mu \mathrm{M}$ PTX. After $24 \mathrm{~h}$ of incubation, cell apoptosis was detected using the FITC Annexin V-staining Kit and a FACScan flow cytometer according to the standard protocol.

\section{Investigation of the endocytosis mechanism by CLSM}

A total of $5 \times 10^{4}$ A549/ADR cells were seeded on a cover slip for $12 \mathrm{~h}$, followed by washing with PBS. The cells were preincubated with $1 \mathrm{mM} 5$-( $N$-ethyl- $N$-isopropyl)amiloride, $10 \mu \mathrm{g} / \mathrm{mL}$ chlorpromazine, and $200 \mu \mathrm{M}$ genistein for $30 \mathrm{~min}$. Control cells were treated without inhibitors, followed by incubation with TPH/C6 $(10 \mu \mathrm{g} /$ $\mathrm{mL}$ ) nanomicelles at $37^{\circ} \mathrm{C}$ for $2 \mathrm{~h}$. The nuclei of the cells were further labeled with $2 \mu \mathrm{g} / \mathrm{mL}$ DAPI for $10 \mathrm{~min}$. After incubation, the A549/ADR cells were imaged by confocal laser scanning microscopy (CLSM) (Zeiss LSM 710). 


\section{Lysosome escape}

CLSM was used for the lysosome escape assay. A549 and A549/ADR seeded in a special confocal microscopy dish (NEST) at a density of $5 \times 10^{4}$ cells/well, respectively. After $24 \mathrm{~h}$, Taxol, TP/C6, and TPH/C6 nanomicelles were added to the media and incubated. At predetermined time intervals $(2 \mathrm{~h}, 4 \mathrm{~h}, 6 \mathrm{~h}$, and $8 \mathrm{~h})$, the cells were washed with cold PBS and then stained with $1 \mu \mathrm{M}$ LysoTracker Red for $30 \mathrm{~min}$ and $2 \mu \mathrm{g} / \mathrm{mL}$ DAPI for $10 \mathrm{~min}$ at $37^{\circ} \mathrm{C}$ in the dark. Subsequently, the cells were washed and observed by CLSM.

\section{Mitochondria localization}

A549 and A549/ADR cells were seeded in a Lab-Tek 8 -well chamber slide at $1.5 \times 10^{4}$ cells per well. After $12 \mathrm{~h}$ of attachment, cells were incubated with TPH/C6 for $6 \mathrm{~h}, 12 \mathrm{~h}$ and $24 \mathrm{~h}$. Mitochondria were labeled with $1 \mu \mathrm{M}$ MitoTracker Red and imaged by CLSM.

\section{Drug content in the isolated mitochondria}

FACScan flow cytometer was applied into drug content in isolated mitochondria assay. A549 and A549/ADR cells, were seeded in 6-well plates at a density of $2 \times 10^{5}$ cells/ well for $48 \mathrm{~h}$, were treated by PBS, Taxol, TP/PTX, TPH/ PTX nanomicells containing $10 \mu \mathrm{M}$ of PTX for $24 \mathrm{~h}$. The cells were then collected and washed by cold PBS twice. Mitochondria isolation was performed according to mitochondria isolation kit protocols (Beyotime Institute of Biotechnology, China). The amount of C6 in mitochondrial was analyzed by FACScan flow cytometer and indicated by fluorescent intensity. The assay was repeated in triplicate.

\section{JC1 assay}

A549 and A549/ADR cells were seeded in a LabTek 8-well chamber slide. Taxol, TP/C6, and TPH/ C6 nanomicelles were incubated with $1.5 \times 10^{4}$ cells for $24 \mathrm{~h}$. A control was included without the NPs. The cells were then washed twice with $\mathrm{PBS}(\mathrm{pH}=7.4)$ and incubated with $10 \mu \mathrm{g} / \mathrm{mL} 5,5^{\prime}, 6,6^{\prime}$-tetrachloro-1,1',3,3'tetraethylbenzimidazolylcarbocyanine iodide (JC1) dye (Beyotime Institute of Biotechnology, China) at $37^{\circ} \mathrm{C}$ for $20 \mathrm{~min}$. Before adding JC1 dye, the cells were visualized using CLSM at a fluorescence emission wave length of $590 \mathrm{~nm}$, and the red fluorescence signal obtained from the NPs was calculated to be deducted from the JC1 fluorescence emission signal for baseline correction. The JC1 signal in the cells was visualized and quantified by CLSM.

\section{Release of cytochrome C}

The release of cytochrome $\mathrm{C}$ from the mitochondria of A549 and A549/ADR cells into the cytosol was measured using a streptavidin-peroxidase immunohistochemical kit (Zhongshan Goldenbridge Biotechnology, Co., Ltd., Beijing, China) [23]. Briefly, after incubation for $24 \mathrm{~h}$, A549 and A549/ADR cells were exposed to Taxol, TP/ C6, and TPH/C6 nanomicelles or fresh medium as a control. The cells were then fixed with paraformaldehyde for 20 min and sequentially treated with Triton $\mathrm{x}-100,3 \%$ $\mathrm{H}_{2} \mathrm{O}_{2}$, and the provided blocking reagent. Next, the cells were incubated with primary antibody overnight at $4{ }^{\circ} \mathrm{C}$. Then, the secondary antibody (provided in the kit) and the enhanced streptavidin HRP conjugate (provided in the kit) were added to the cells. After color development, the release of cytochrome $\mathrm{C}$ was observed under a light microscope.

\section{Caspase activation}

A549 and A549/ADR cells were cultured for $12 \mathrm{~h}$ and then treated with Taxol, TP/PTX, and TPH/PTX nanomicelles. Controls samples were prepared by adding blank medium. The final concentration of PTX was $10 \mu \mathrm{M}$. After $12 \mathrm{~h}$ of incubation, the cells were harvested, lysed, and analyzed by Western blotting. The following antibodies were used: anti-caspase-9, anti-caspase-3, Bcl2, and Bax (all from Cell Signaling, Beverly, MA, USA) [24].

\section{Xenograft tumor model establishment and biodistribution analyses}

4T1/ADR-bearing mice BALB/C mice (5 weeks old, weighing 16-18 g) were cultured in our Lab. All animal experiments were carried out in compliance with the guidelines of the Institutional Animal Care and Use Committee of Guangzhou Medical University. For establishment of the subcutaneous xenograft tumor models, 4T1/ADR cells $\left(3 \times 10^{6}\right)$ were administered by subcutaneous injection into the right flanks of the mice. When the volumes of the tumors reached approximately 200-300 $\mathrm{mm}^{3}$, the mice were administered physiological saline, free DIR and DIR-loaded nanomicelles via tail vein injection. At predetermined time points $(2 \mathrm{~h}, 6 \mathrm{~h}$, $12 \mathrm{~h}$ and $24 \mathrm{~h}$ ), images were obtained with an NIR fluorescence imaging system. The mice were sacrificed by dislocation of the cervical vertebra $24 \mathrm{~h}$ after injection. Then, the tumor and organs, including the heart, liver, spleen, lung and kidney, were collected and analyzed in the imaging system.

\section{Antitumor efficacy in vivo}

Twenty tumor-bearing mice (A549/ADR) were used when the volume of the tumors reached approximately $220-230 \mathrm{~mm}^{3}$. The animals were randomly divided into four groups, namely, groups treated with saline, Taxol, TP/PTX, and TPH/PTX nanomicelles $(\mathrm{n}=5)$, and treated 
at days $17,19,21,23,25,27$, and 29 via the tail vein. The final concentration of PTX was $10 \mathrm{mg} / \mathrm{kg}$. The mice were then monitored with respect to tumor progression and weight loss every other day, and the tumor volumes were calculated as the length $\times$ width $^{2} / 2\left(\mathrm{~mm}^{3}\right)$. The tumor volume inhibition rate at day 29 was calculated using the formula $\mathrm{Rv}=100 \%-(\mathrm{V}$ drug /V saline $) \times 100 \%$, where $\mathrm{V}$ drug is the tumor volume after drug treatment, and $\mathrm{V}$ saline is the tumor volume after treatment with physiological saline. H\&E staining assays were further performed. Moreover, an immunohistochemical assay of the tumor tissue was also performed to evaluate the release of cytochrome C. H\&E stained to examine the tissue toxicity of the therapeutic agents.

\section{Antitumor effects on lung metastasis in the drug-resistant breast cancer-bearing mouse models}

Twenty-five BALB/C nude mice (female, 6-8 weeks old) were divided into five groups (five mice per group). On day 0 , all of the mice were administered 1 million 4T1/ ADR tumor cells by intravenous injection to generate a breast cancer-bearing mouse model with lung metastasis. At 6, 8, 10, 13 and 15 days, the four groups were treated by systemic administration of PBS, Taxol, TP/ PTX nanomicelle, and TPH/PTX nanomicelle. The final concentration of PTX was $10 \mathrm{mg} / \mathrm{kg}$. On day 15 , the mice were sacrificed, and the light signal and tumor number from the lung was then immediately captured and counted to further validate tumor growth, respectively.

\section{Statistical analysis}

Statistical analyses were performed using GraphPad Prism 5.0 software. Comparisons were statistically assessed by one-way ANOVA. The data are presented as the mean \pm standard deviation (SDs).

\section{Results}

\section{Synthesis and characterization of TPH/PTX}

Recently, it was demonstrated that TPP, as part of the vectors, can transfer chemotherapeutic drugs into cancer cells and simultaneously target mitochondria in cancer cells [25]. In this study, F127 was conjugated to $\mathrm{COOH}-$ TPP by esterification using DCC/DMAP. This reaction produced OH-PF127-TPP (TP). The average diameter of TP/PTX nanomicelles was approximately $135 \mathrm{~nm}$, with a positive zeta potential of $+13.2 \mathrm{mV}$. To better overcome the drug resistance of cancer cells and reduce the high positive zeta potential, HA was conjugated to TP by esterification using DCC/DMAP. HA-PF127-TPP (TPH) was finally produced. The average diameter of the TPH nanomicelles was approximately $142 \mathrm{~nm}$, which was approximately $7 \mathrm{~nm}$ higher than that of the TP/PTX nanomicelles, with a negative potential of $-24.65 \mathrm{mV}$ (Table 1). The route used for the synthesis of TPH is shownin Scheme 2. The ${ }^{1} \mathrm{H}-\mathrm{NMR}$ and IR spectrum complete peak assignments of the TPH copolymer were showed in Fig. 1a, b, respectively.

The TEM assay showed that all the nanomicelles were spherical (Fig. 2a). The diameter of the TPH/PTX nanomicelles was slightly increased compared with those of the TP/PTX and blank nanomicelles, indicating successful modification of HA on TP.

To investigate the stability of TPH/PTX, TP/PTX and TPH/PTX nanomicelles were added to PBS ( $\mathrm{pH}$ 7.4) containing $10 \% \mathrm{FBS}$ at $37{ }^{\circ} \mathrm{C}$. The particle size showed no significant change over $96 \mathrm{~h}$ (Fig. 2b), implying a strong negative potential and that the hydrophilic HA shell protected TP/PTX from opsonization by plasma proteins for further enhancement of stability. The zeta potential of TPH/PTX, however, rapidly increased when the nanomicelles were exposed to HAase with obvious $\mathrm{pH}$ dependence; the values were $+9.48 \mathrm{mV}$ at $\mathrm{pH} 5.6$ and $+12.85 \mathrm{mV}$ at $\mathrm{pH} 4.5$, from $-4.58 \mathrm{mV}$ at $\mathrm{pH} 7.4$, after a 10 -h incubation, implying that TPH/PTX nanomicelles escaped from the acid lysosome through the proton sponge (Fig. 2c).

As shown in Fig. 2d, the release percentage of PTX at $10 \mathrm{~h}$ from TPH/PTX nanomicelles was approximately $30 \%$ at $\mathrm{pH}$ 7.4. However, at $\mathrm{pH} 5.0$, the cumulative release of PTX from TPH/PTX was increased to $68 \%$ at $72 \mathrm{~h}$, and at $\mathrm{pH} 4.5$, the cumulative release increased to $83 \%$ at $72 \mathrm{~h}$, indicating that the release profiles are dependent on the acid concentration.TP/PTX nanomicelles are similar to TPH/PTX, remaining approximately unchanged for $72 \mathrm{~h}$ and exhibiting a markedly prolonged release.

\section{In vitro antitumor activity}

To understand the effect of the NP-mediated mitochondrial damage in cancer cells, A549 and A549/ADR cells were treated with TPH/PTX nanomicelles for $24 \mathrm{~h}$, $48 \mathrm{~h}$, and $72 \mathrm{~h}$, followed by evaluation of cell viability

Table 1 Characterization of nanomicelles

\begin{tabular}{lllcc}
\hline Formulation & Particle size $(\mathbf{n m})$ & PDI & Zeta potential & Encapsulation (\%) \\
\hline Blank nanomicelles & $126 \pm 9.56$ & $0.254 \pm 0.015$ & $-27.36 \pm 3.65$ & \\
TP/PTX nanomicelles & $135 \pm 8.65$ & $0.281 \pm 0.020$ & $13.24 \pm 3.45$ & $90.51 \pm 9.23$ \\
TPH/PTX nanomicelles & $142 \pm 8.35$ & $0.235 \pm 0.020$ & $-24.65 \pm 2.75$ & $92.35 \pm 9.05$ \\
\hline
\end{tabular}


<smiles>CC(C)C(=O)CCCCC[P+](c1ccccc1)(c1ccccc1)c1ccccc1</smiles>

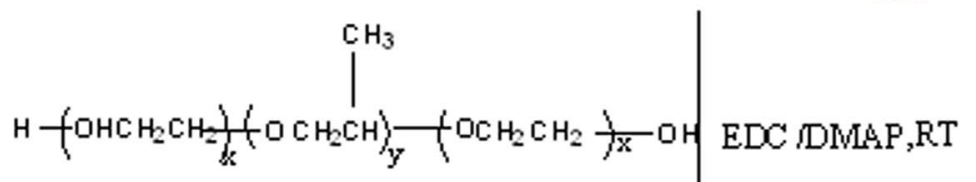

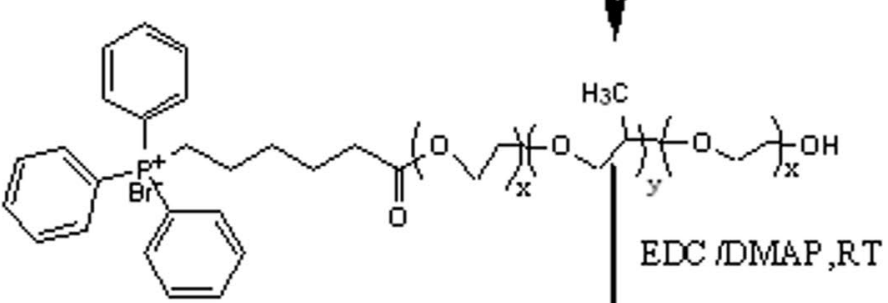

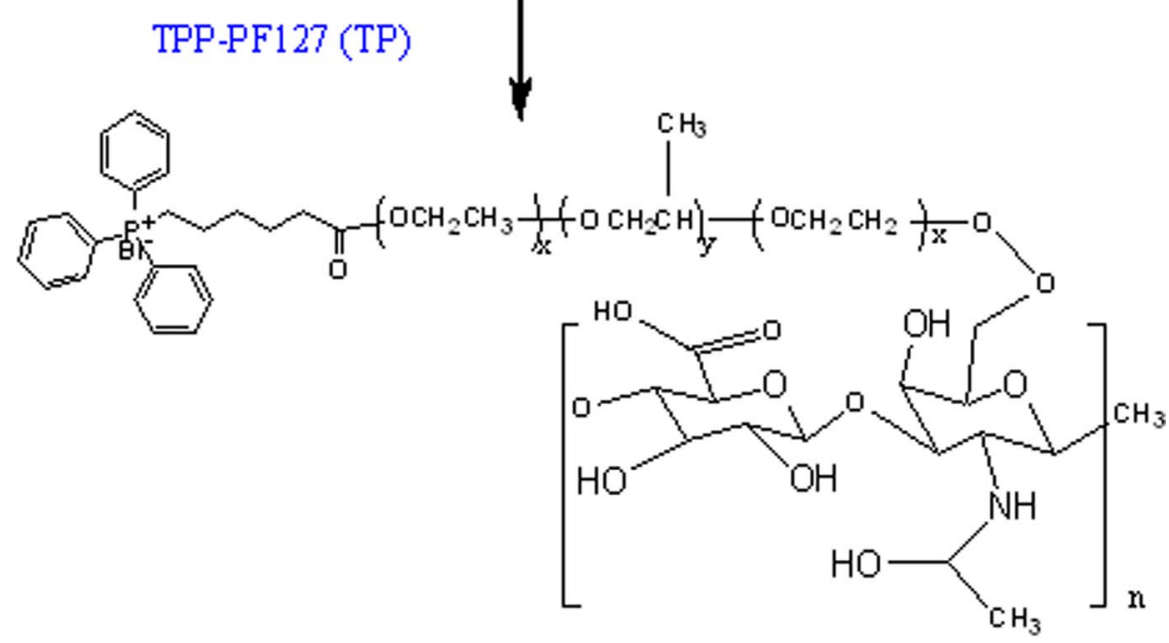

TPP-PF 127-HA (TPH)

Scheme 2 Synthetic scheme showing the various steps required to prepare TPH

by proliferation assays. As shown in Fig. 3a, cancer cell viability decreased with increasing PTX concentrations and extended incubation times. TP/PTX nanomicelles showed lower anti-A549 cell activity than Taxol at all doses, but TP/PTX nanomicelles showed greater inhibition of A549/ADR than Taxol alone (Fig. 3b). Compared with Taxol and TP/PTX nanomicelles, TPH/ PTX showed high antitumor activity with extended duration of incubation ( $24 \mathrm{~h}, 48 \mathrm{~h}$ and $72 \mathrm{~h}$ ). In particular, for A549/ADR cancer cells, TPH/PTX exhibited much lower IC 50 values $(35.25,16.41$, and $9.66 \mu \mathrm{M})$ than Taxol $(70.48,61.52$, and $58.53 \mu \mathrm{M})$ and TP/PTX nanomicelles $(47.39,42.87$, and $32.38 \mu \mathrm{M})$ at $24 \mathrm{~h}, 48 \mathrm{~h}$, and $72 \mathrm{~h}$ (Table 2), which might be attributed to the efficient internalization of nanomicelles with HA serving as the active targeting ligand that specifically binds 


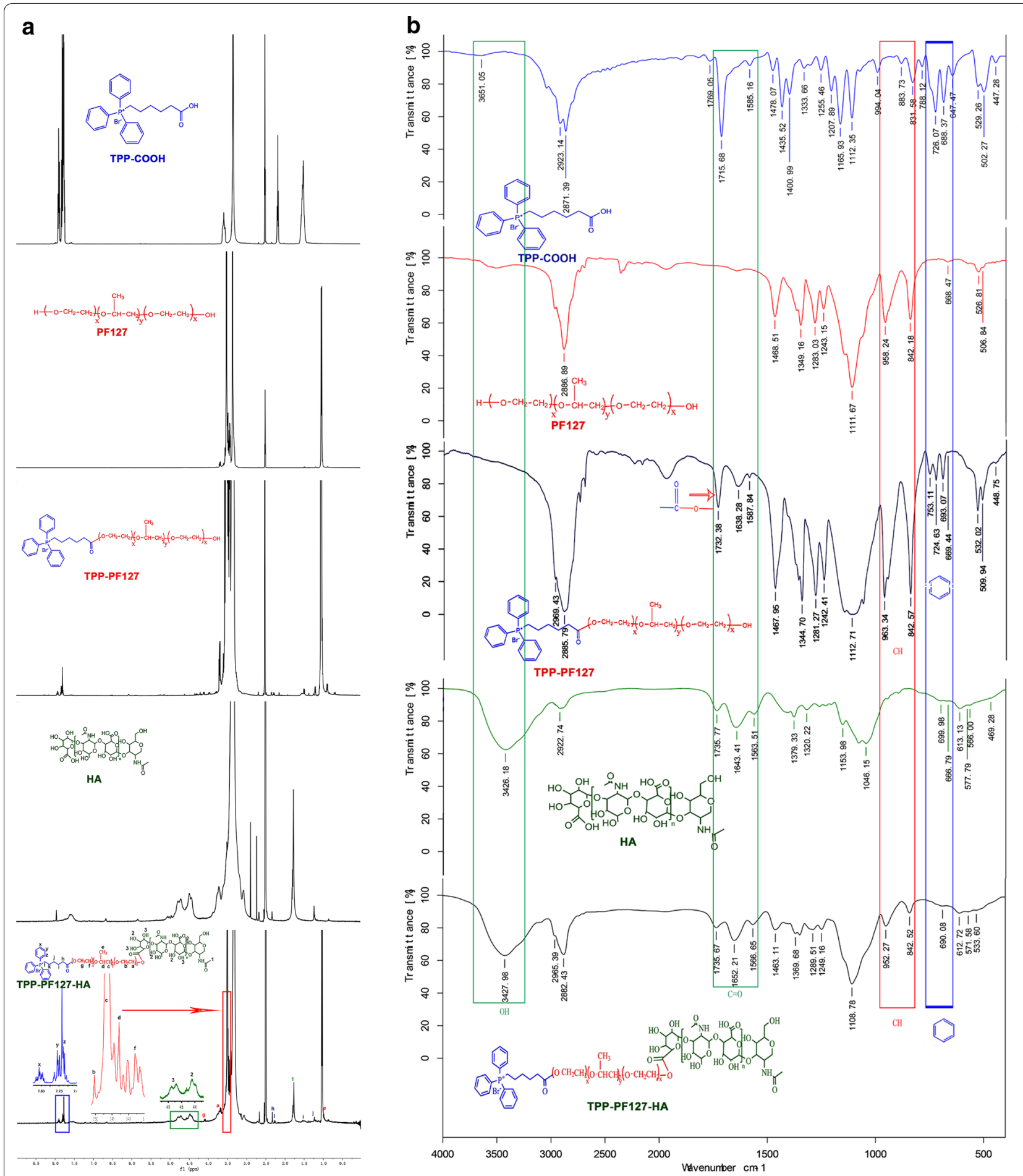

Fig. $1{ }^{1} \mathrm{H}$ NMR (a) and IR (b) of PF127, TPP, HA, TP, and TPH polymers

CD44 receptors overexpressed in many tumor cells [26] and mitochondrial target.

The in vitro biocompatibility of TP and TPH polymer was further studied by performing the hemo-compatibility test (Fig. 3c). The hemolysis levels of TP and TPH nanomicelles were negligible with hemolytic ratios of 0.001 vitro biocompatibility of TP and $\mathrm{TPH}$ polymer was further studied by performing 


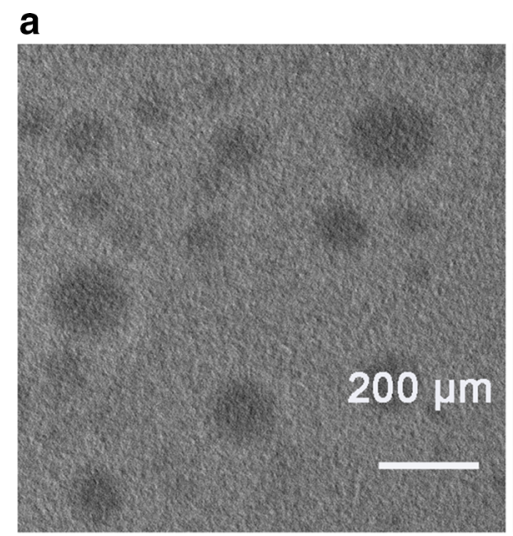

Blank Nanomicelles

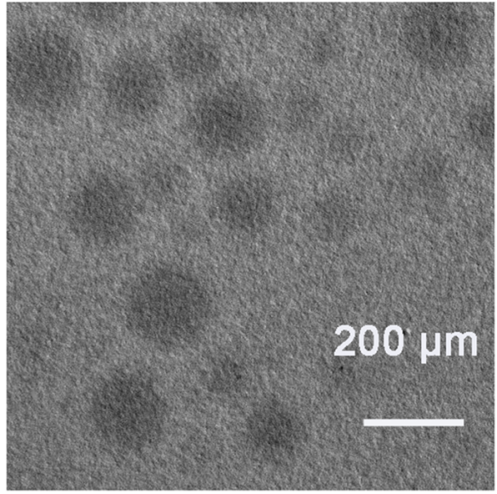

PT/PTX Nanomicelles

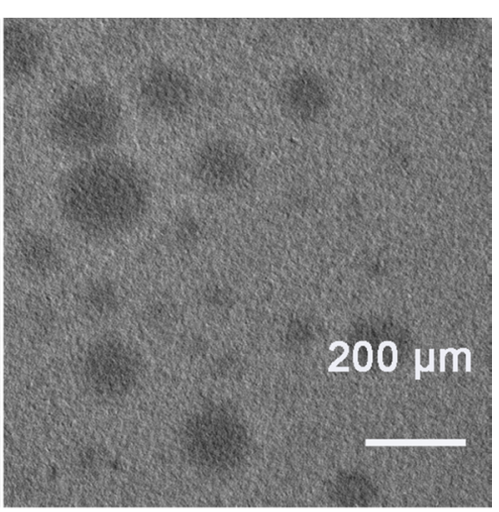

HPT/PTX Nanomicelles
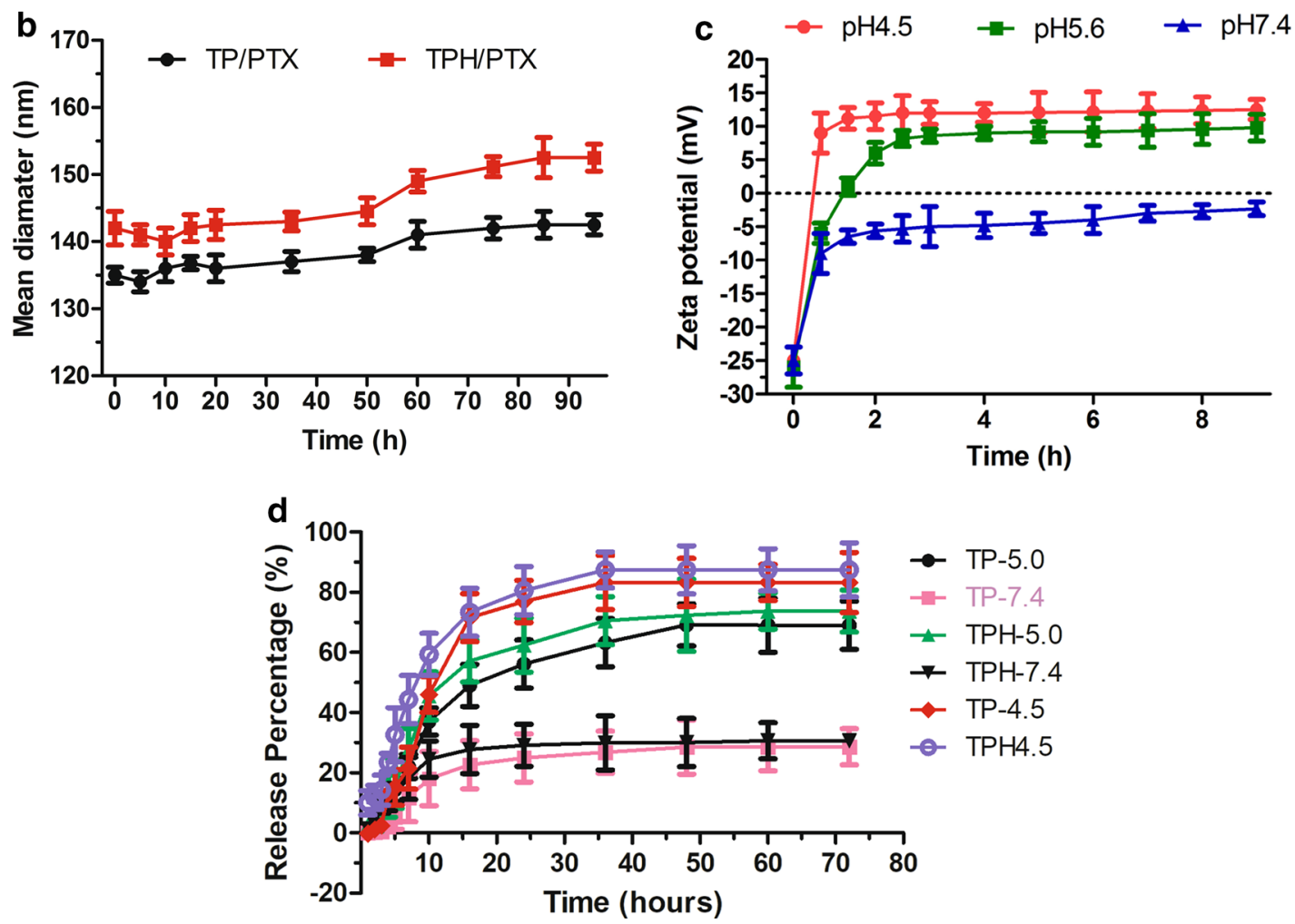

Fig. 2 Characterization of all nanomicells. a Representative TEM images of all nanomicells. $\mathbf{b}$ Size change of all nanomicells after incubation in PBS containing $10 \% \mathrm{FBS}$ at $37^{\circ} \mathrm{C}$. c PTX's release from all nanomicells at $\mathrm{pH}$ 7.4. $\mathbf{d}$ Change in the zeta potential of TPH/PTX nanomicells after incubation with HAase $(0.5 \mathrm{mg} / \mathrm{mL})$ at different $\mathrm{pH}$. Data are presented as the mean $\pm \mathrm{SD}(\mathrm{n}=3)$

the hemo-cafter co-cultured with PBS, TP $(0.25 \mathrm{mg} / \mathrm{mL}$, $0.5 \mathrm{mg} / \mathrm{mL}, 1.25 \mathrm{mg} / \mathrm{mL}), \mathrm{TPH}(0.25 \mathrm{mg} / \mathrm{mL}, 0.5 \mathrm{mg} / \mathrm{mL}$, $1.25 \mathrm{mg} / \mathrm{ml}$ ), respectively. In addition, the cytotoxicity of drug free nanomicelles (for example, TP, TPH), were also assayed in lung cancer cells, and cell cytotoxicity was hardly observed, indicating that these vectors are biocompatible and non-toxic to tissues and cells (Additional file 1: Figure S1).

\section{Cellular uptake}

CLSM can be used to study the cellular uptake of nanomicelles. As shown in Fig. 4a, the fluorescence intensity of $\mathrm{TPH} / \mathrm{C} 6$ increased 4.8 -fold compared with that of the nontargeted TP/C6 nanomicelles in the HA-free group. However, when TPH/C6 was added to A549/ADR cells that contained saturated HA, the cellular uptake efficiency of the targeted TPH/C6 decreased 


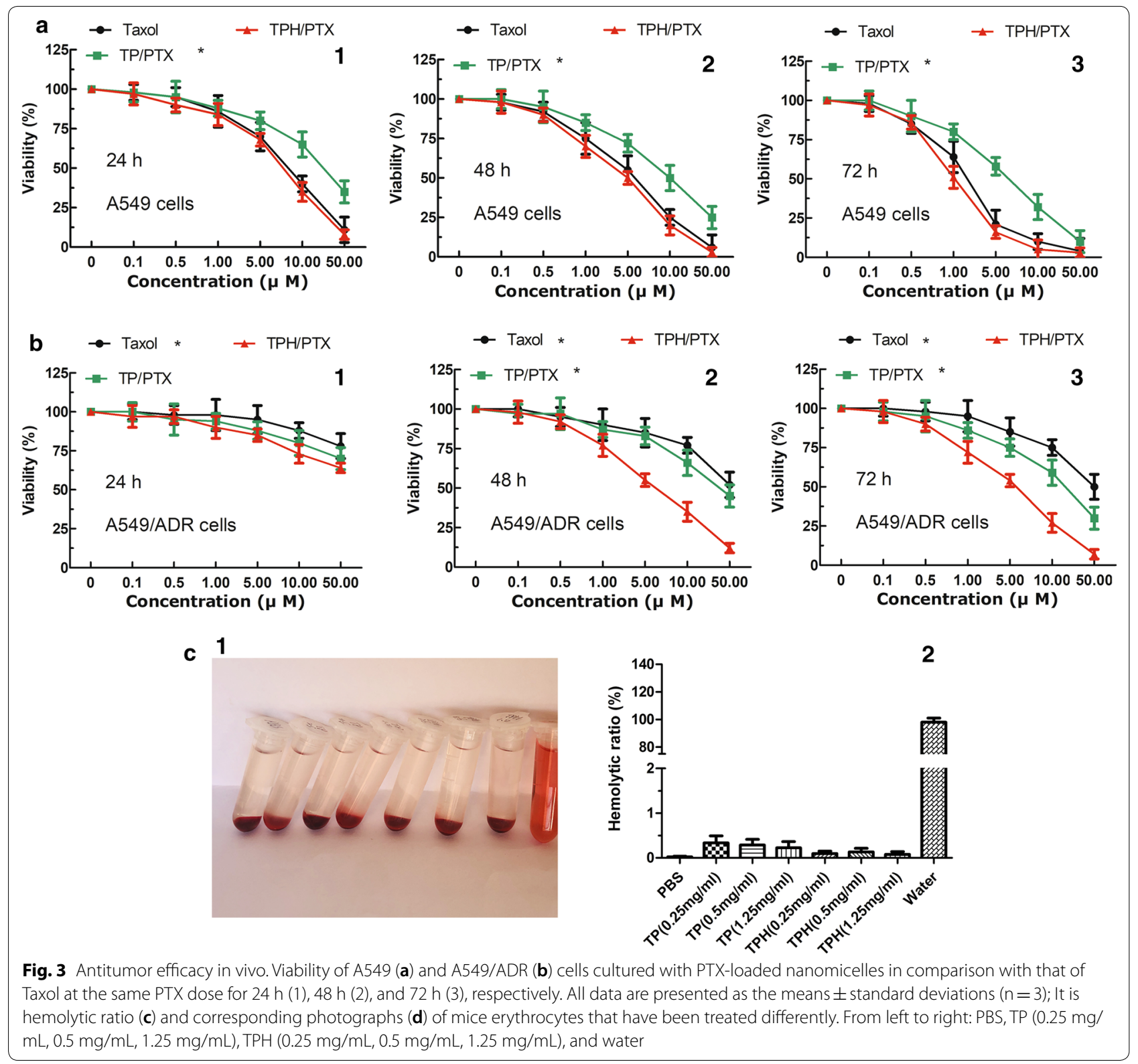

Table 2 IC50 values of Taxol and every PTX loaded nanomicelles on A549 and A549/PTX cells after 24 h, 48 h, and 72 h incubation $(\mathbf{n}=\mathbf{5})$

\begin{tabular}{|c|c|c|c|c|c|c|}
\hline \multirow[t]{2}{*}{ Formulation } & \multicolumn{3}{|l|}{ A549 } & \multicolumn{3}{|l|}{ A549/ADR } \\
\hline & Taxol & TP/PTX & TPH/PTX & Taxol & TP/PTX & TPH/PTX \\
\hline $24 \mathrm{~h}$ & $18.64 \pm 0.53$ & $36.54 \pm 2.31$ & $14.79 \pm 1.56$ & $70.48 \pm 2.86$ & $47.39 \pm 3.25$ & $35.25 \pm 2.54$ \\
\hline $48 \mathrm{~h}$ & $9.44 \pm 1.32$ & $28.22 \pm 2.15$ & $6.68 \pm 1.23$ & $61.52 \pm 2.30$ & $42.87 \pm 2.36$ & $16.41 \pm 1.35$ \\
\hline $72 \mathrm{~h}$ & $4.71 \pm 0.45$ & $14.91 \pm 1.65$ & $3.07 \pm 0.45$ & $58.53 \pm 1.32$ & $32.38 \pm 3.12$ & $9.66 \pm 1.25$ \\
\hline
\end{tabular}




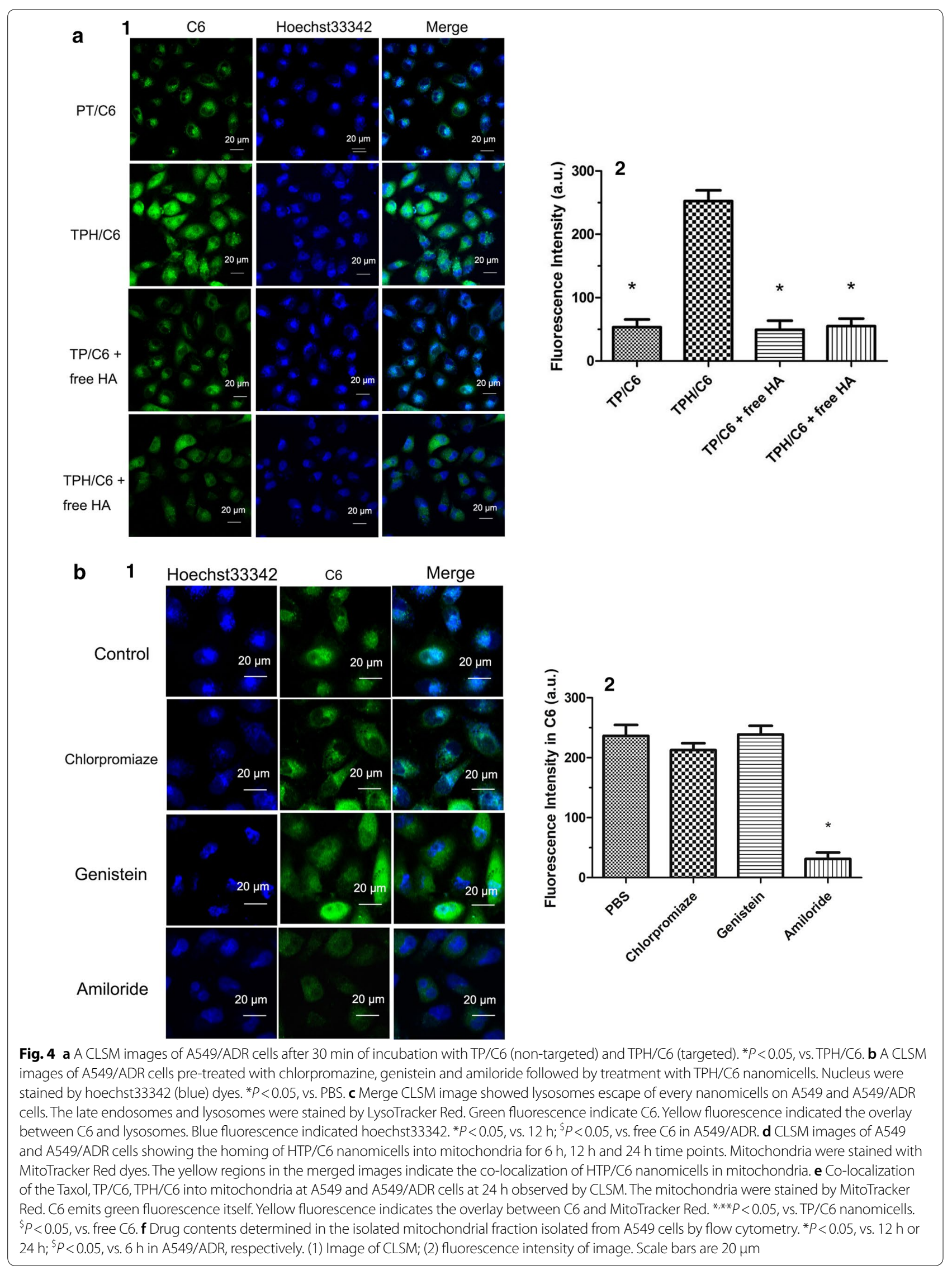



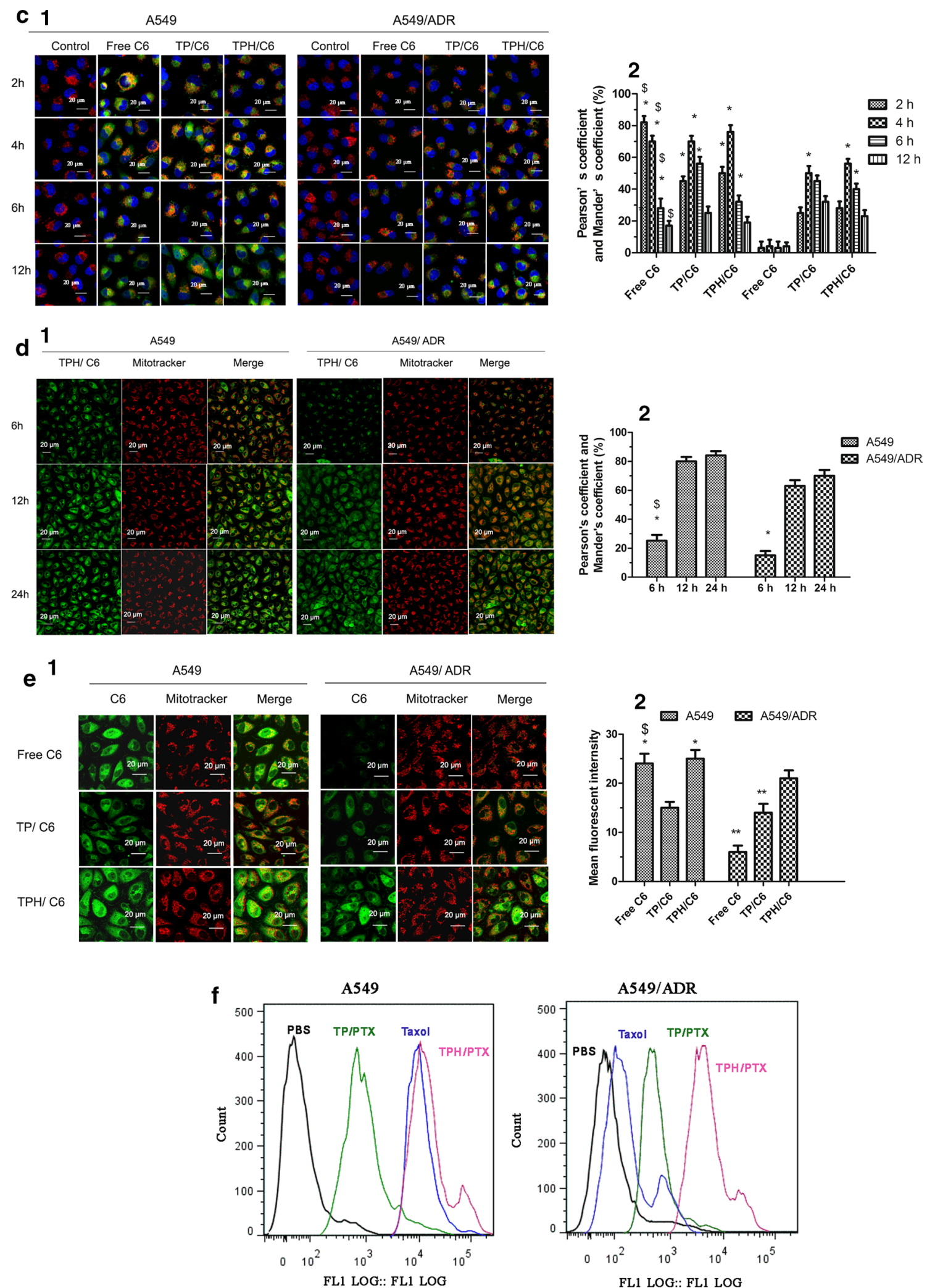

Fig. 4 continued 
substantially due to the competitive binding of free HA and CD44 on the cancer cells, suggesting that the endocytosis of TPH/C6 nanomicelles by A549/ADR cells was greatly facilitated by CD44-mediated internalization.

The highly hydrophobic free $\mathrm{C} 6$ readily diffused into the A549 cells and drastically induced cellular accumulation. However, the fluorescence intensity of C6 changed weakly in the resistant A549/ADR cells. Interestingly, the $\mathrm{C} 6$ green fluorescence of TPH/C6 nanomicelles was more intense than that of TP/C6 nanomicelles or free C6 in both A549 and A549/ADR cells. Importantly, the intense green fluorescence of TPH/C6 in A549/ADR cells was similar to that in A549 cells, indicating that the tumor-targeting and mitochondria-targeting TPH/PTX nanomicelles can overcome drug resistance.

\section{Mechanism of endocytosis}

To investigate the endocytosis machinery involved, A549/ADR cells preincubated with different endocytosis inhibitors (genistein, chlorpromazine and amiloride) were treated with TPH/C6 nanomicelles for $2 \mathrm{~h}$. As shown in Fig. 4b, genistein- and chlorpromazine-pretreated cells endocytosed TPH/C6 nanomicelles to the same extent as non-inhibitor-treated control cells. On the other hand, the amiloride complex exhibited the most significant inhibitory effect among the three endocytic inhibitors, indicating that macropinocytosis-mediated endocytosis was the main pathway for endocytosis of TPH/C6 nanomicelles.

\section{Lysosome escape}

The TPH/PTX nanomicelles must escape lysosomes before being trafficked to mitochondria after accumulation in the acidic lysosomes. Further investigation of the mechanism underlying lysosome escape in A549/ADR cells showed that colocalization of the red fluorescence of lysosomes and green fluorescence of C6 led to a merged yellow signal at different time points. Figure $4 \mathrm{c}$ demonstrates that all nanomicelles exhibited obvious merged signals (weak red, strong yellow, weak yellow, and strong green) at $2 \mathrm{~h}, 4 \mathrm{~h}, 6 \mathrm{~h}$, and $12 \mathrm{~h}$, respectively. Compared with other groups, TPH/C6 was mainly accumulated in lysosomes at $4 \mathrm{~h}$ and separated from the lysosomes and completely distributed in the cytoplasm at $12 \mathrm{~h}$. Although lysosomal sequestration of the drug pumped out A549/ADR cells led to the lose of large amounts of free C6, the fluorescence intensity of TPH/C6 in the cytoplasm of A549/ADR cells approached that in A549 cells, suggesting that most TPH/ C6 can successfully escape lysosome in $12 \mathrm{~h}$.

\section{Colocalization in the mitochondria}

After escaping from lysosomes, TPH/C6 nanomicelles should be trafficked to mitochondria to deliver their payloads. To observe the localization in mitochondria, TPH/C6 nanomicelles were incubated with A549 and A549/ADR cells for three different durations $(6 \mathrm{~h}, 12 \mathrm{~h}$ and $24 \mathrm{~h}$ ), followed by staining of the mitochondria with MitoTracker red dye. The merged yellow signal, which came from the green fluorescent TPH/C6 nanomicelles colocalized with red fluorescent-tagged mitochondria, was imaged by CLSM, as shown in Fig. 4d. Pearson's coefficient and Mander's coefficient-based quantification of the volume of colocalization demonstrated $80.5 \%$ and 84.2\% (A549) and 63.5\% and 70\% (A549/ADR) overlapping regions at $12 \mathrm{~h}$ and $24 \mathrm{~h}$, respectively, which were more yellow than the signals observed at $6 \mathrm{~h}(25.2 \%$, A549; 16.8\%, A549/ADR), moreover, the merged light yellow signal from TPH/C6 nanomicells significantly was showed, compared with TP/C6 nanomicells (Fig. 4e), indicating that $\mathrm{TPH} / \mathrm{C} 6$ nanomicelles localized in mitochondria over $24 \mathrm{~h}$.

To further confirm the localization of TPH/C6 in mitochondria, all nanomicelles were incubated with A549/ ADR cells for $24 \mathrm{~h}$. Flow cytometry assays demonstrated that the mean fluorescence intensity of the isolated mitochondria in TPH/C6 nanomicelles was the highest compared to that of free $\mathrm{C} 6$ and TP/C6 nanomicelles (Fig. 4f). The result further verified the accumulation of the nanomicelles in mitochondria, which supported the mitochondrial colocalization observed by CLSM.

\section{Mitochondrial outer membrane permeabilization.}

After trafficking into mitochondria and successful release of drugs, JC1 was used to investigate the effect of TPH/ PTX nanomicelles on the mitochondrial membrane potential $(\Delta \psi \mathrm{m})$. JC-1, as a lipophilic cationic dye, can selectively swarm into mitochondria and reversibly change the red signal to green when the mitochondrial membrane potential is reduced. The strong green fluorescence indicated a decrease in $\Delta \psi \mathrm{m}$. Figure 5a demonstrates that the green/red ratios induced by PBS, Taxol, TP/PTX nanomicelles, and TPH/PTX nanomicelles in A549/ADR cells were $0.98 \pm 0.07,1.09 \pm 0.05,2.85 \pm 0.10$, $4.65 \pm 0.11$, respectively. The values were similar to those observed in A549 cells $(1.01 \pm 0.07,5.15,3.56 \pm 0.11$, $5.25 \pm 0.04)$. By comparison, the decrease of $\Delta \psi \mathrm{m}$ of TPH/PTX nanomicells was the most significant, which was almost 4.26-times higher than that of the Taxol group in A549/ADR (Fig. 5b).

Mitochondrial outer membrane permeabilization (MOMP) leads to the release of cytochrome $\mathrm{C}$ from the intermembrane space (IMS) [23]. The release of cytochrome $\mathrm{C}$ from mitochondria was observed by optical microscopy using a streptavidin-peroxidase immunohistochemical kit. As shown in Fig. 5c, compared to the control, Taxol and TP/PTX nanomicelles exhibited 


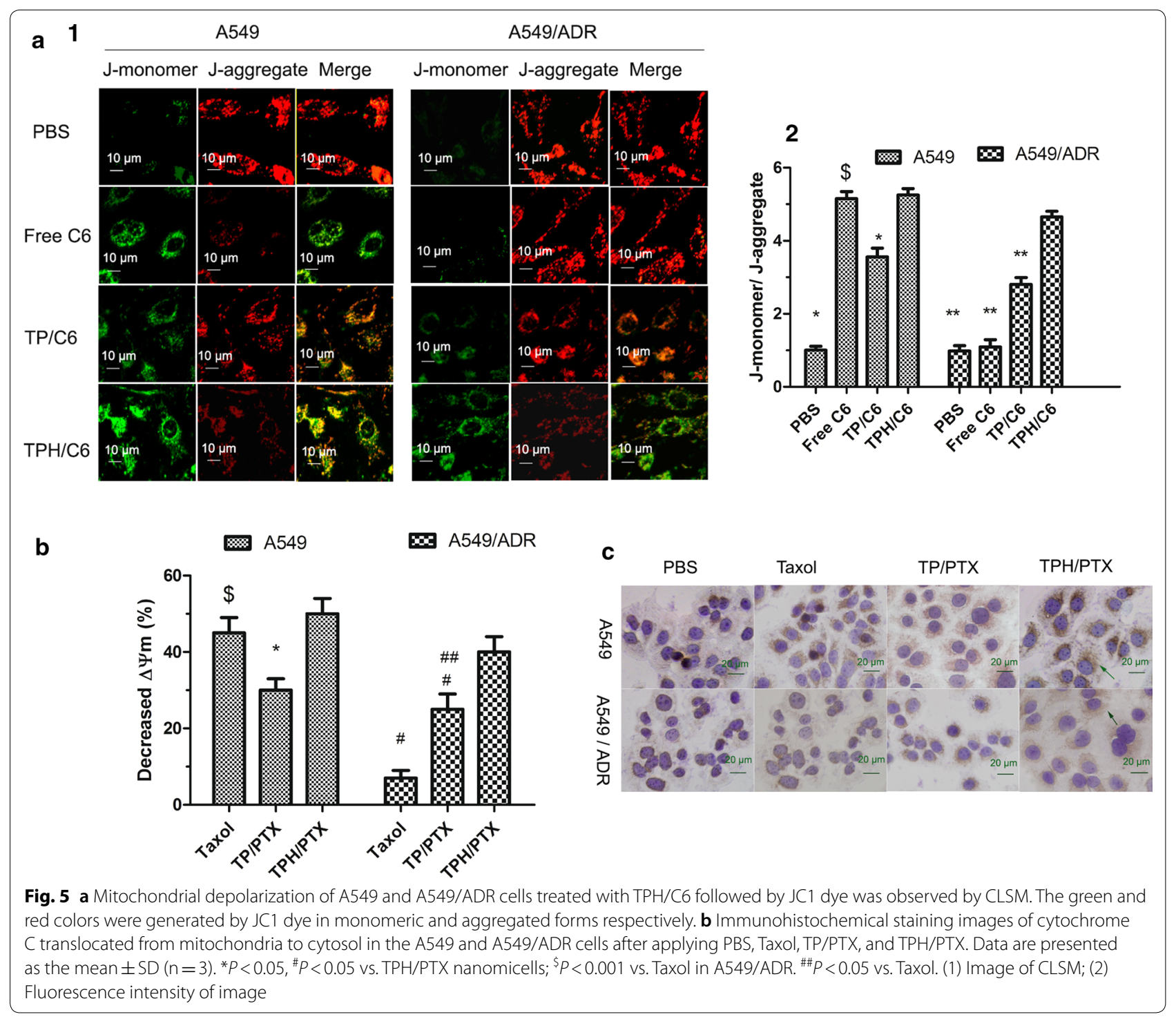

release of small amounts of cytochrome C (brown). The highest release in A549 and A549/ADR cells was observed with TPH/PTX nanomicelles, which was consistent with the results of the mitochondrial membrane potential and cell apoptosis experiments. The release of cytochrome $\mathrm{C}$ may be related to the opening of the MPTP (mitochondrial permeability transition pore) as the direct effect of the PTX molecules or the activation of the proapoptotic protein Bax [27].

\section{In vitro apoptosis-inducing effect}

The Annexin V-FITC Apoptosis Detection Kit was used to test whether TPH/PTX nanomicelles can induce apoptosis in drug-resistant cells. Figure 6a depicts the apoptosis-inducing effects of all the nanomicelles in A549 and A549/ADR cells. After the addition of PBS, Taxol, TP/PTX nanomicelles, and TPH/PTX nanomicelles, the apoptosis rates in A549/ADR cells were 2.15, 6.69, 22.10, and $42.80 \%$, respectively, while those in A549 cells were $3.44,43.10,29.1$, and $48.40 \%$. These findings further indicated that TPH/PTX nanomicelles could effectively overcome drug resistance.

\section{Apoptosis-related signaling pathways Caspase activities}

Western blotting was used to measure the activities of caspase-9 and caspase-3. As shown in Fig. 6b, TPH/PTX nanomicelles significantly enhanced the activities of caspase- 3 and caspase- 9 in both A549 and A549/ADR cells. Interestingly, the expression of caspase- 3 and caspase- 9 


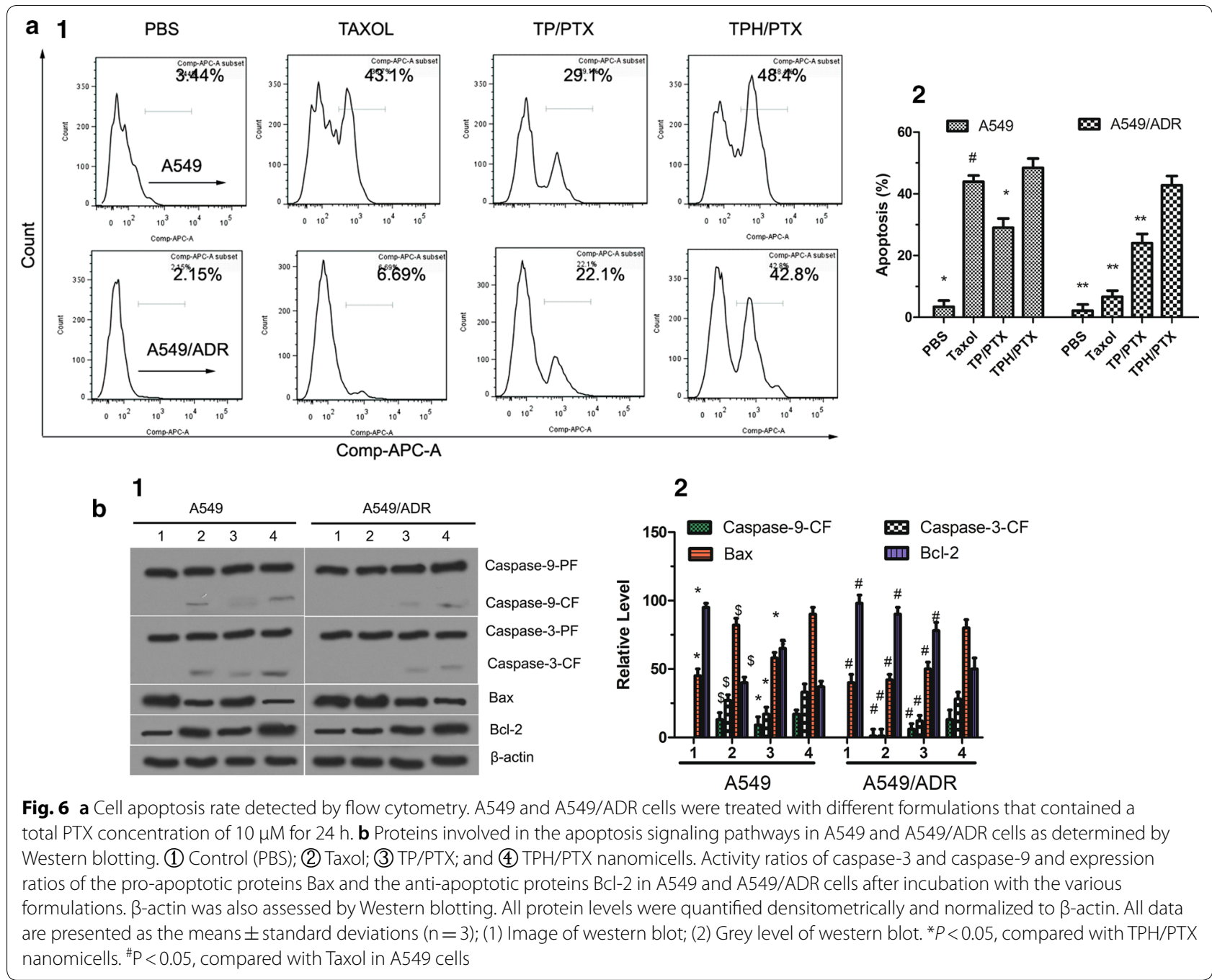

in response to TPH/PTX nanomicelles was nearly equivalent in A549 and A549/ADR cells, suggesting that intrinsic apoptosis was activated by TPH/PTX nanomicelles.

\section{Expression of BCl-2 family proteins}

Bax, as a proapoptotic member of the Bcl-2 family, functions as a regulator of apoptosis, while the anti-apoptotic members of the Bcl-2 family (such as Bcl-2) play a critical role in cell survival by interfering with the process of programmed cell death [28]. In the current study, the TPH/PTX nanomicelles enhanced proapoptotic protein (Bax) expression and reduced antiapoptotic protein (Bcl-2) expression in A549 and A549/ADR cells (Fig. 6b). $\mathrm{TPH} / \mathrm{PTX}$ nanomicelles showed a positive outcome compared to the Taxol and TP/PTX nanomicelles, indicating that TPH/PTX nanomicelles could increase the apoptosis of drug-resistant A549/ADR cells by activating proapoptotic proteins and suppressing antiapoptotic proteins.
In vivo imaging of drug-resistant cancer xenografts in mice The biodistribution of DIR was observed using an NIR reflection fluorescence imaging system and quantified by region-of-interest (ROI) analysis in drug-resistant breast cancer xenografts in mice. Figure 7 a shows that only weak fluorescence at the tumor site was observed in the free DIR group until $24 \mathrm{~h}$ after injection. In contrast, at $6 \mathrm{~h}, \mathrm{TPH} / \mathrm{DIR}$ nanomicelles showed fairly strong fluorescence compared with the other groups, and then, the signals gradually became strong, possibly due to targeting of the $\mathrm{CD} 44$ receptor in the medium.

The major organs and the tumors were excised for ex vivo imaging at $24 \mathrm{~h}$ after injection. ROI analysis was used to quantitatively determine the fluorescence intensity. As shown in Fig. 7b, the TPH/DIR nanomicelle group revealed the strongest fluorescence signal in tumors, and its fluorescence intensity was 5.76 -fold and 2.04-fold higher than that of free DIR and TP/DIR nanomicelle group, respectively. 

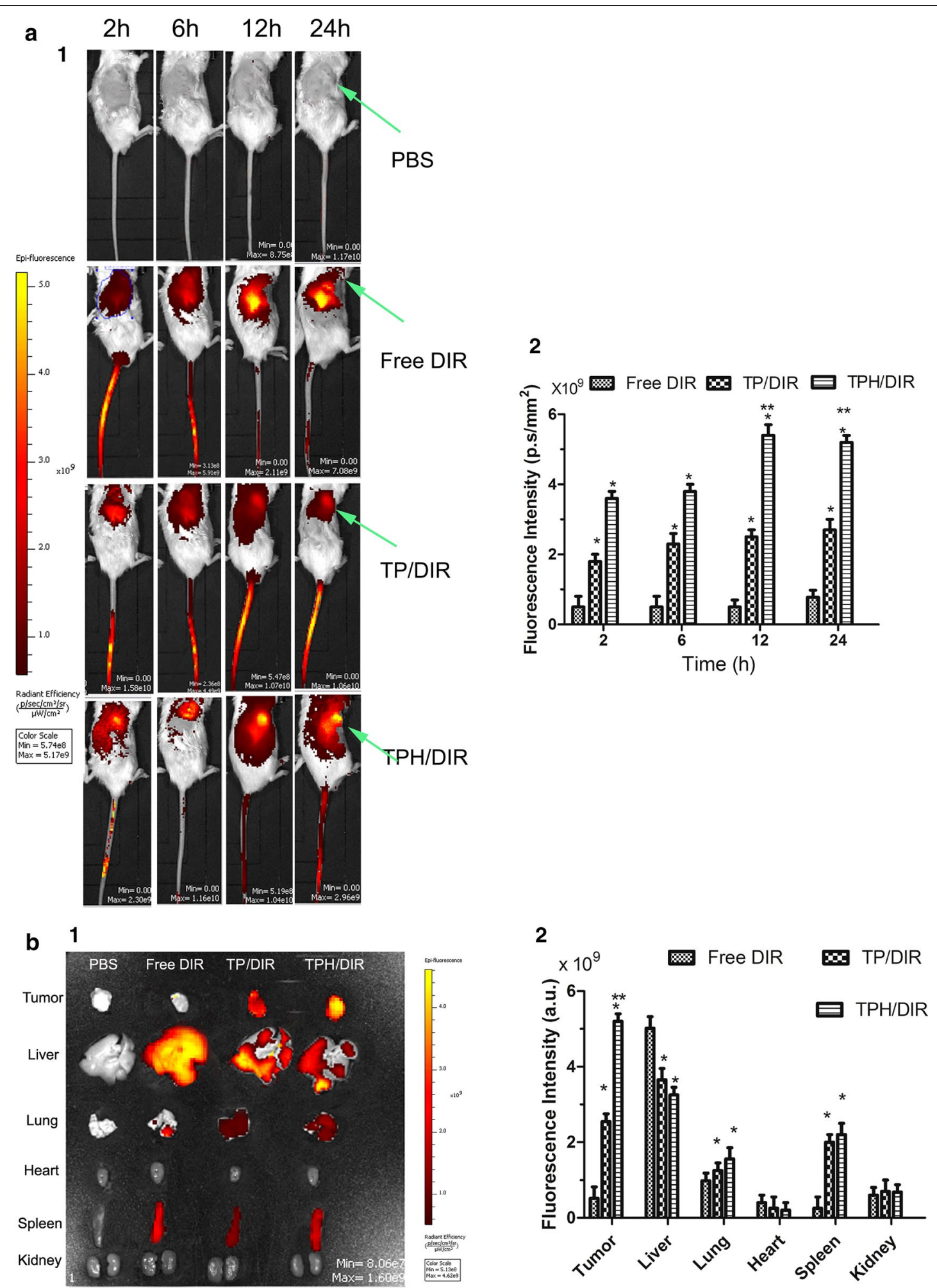

Fig. 7 Tumor target ability of every formulations in 4T1/ADR cells xenografts in BALB/c mice after i.v. of free DIR, TP/DIR, TPH/DIR nanomicells. a In vivo real-time non-invasive whole-body imaging. $\mathbf{b}$ Ex vivo fluorescence of tumors and organs isolated from 4T1/ADR cells xenografts in BALB/C mice. (1) Image of the distribution of drugs in the body or tumors and organs. (2) Fluorescence intensity of image. Data are presented as the mean $\pm S D(n=3) .{ }^{*} P<0.05$ vs. free $D I R ;{ }^{* *} P<0.01$ vs. TPH/DIR for $2 h, 6 h$, respectively 
(See figure on next page.)

Fig. 8 Anticancer efficacy and preliminary safety evaluation in resistant cancer xenografts. a Tumor images (1) and tumor growth inhibition graph (2) and tumor weight (b) for a murine model with A549/ADR xenografts after intravenous injection with the different formulations. c The tumor inhibitory rate (TIR). The TIR is calculated using the following equation: TIR $(\%)=[1-X / Y] \times 100 \% . X$, the average weights of the tumors from the experimental groups; $Y$, the average weights of the tumors from control groups). $\mathbf{d}$ The expression of cytochrome $\mathrm{C}$ of the tumor tissues by immunohistochemistry assay. Images of lung cancer metastasis (e1) and tumor number (e2) for a murine model with 4T1/ADR xenografts after intravenous injection with the different formulations. Body weight $(\mathbf{f})$ and H\&E (g) stained organ slices from the A549/ADR-bearing nude mice treated with all formulations in vivo. The data are presented as the means \pm standard deviations $(n=5) ; * P<0.05,{ }^{*} P<0.001$ compared with TPH/PTX nanomicells; ${ }^{* *} P<0.05$, compared with TP/PTX nanomicells

\section{Anticancer efficacy in resistant human lung cancer xenografts}

The analysis of different formulations with the same dose of PTX using resistant A549/ADR-xenografted nude mice revealed that the most significant antitumor activity was obtained with the TPH/PTX nanomicelles (Fig. 8a, b). On day 29 , the mice treated with TPH/PTX nanomicelles achieved the highest tumor inhibition (81.7\%), which was 8.09-fold and 2.12-fold higher than that of the Taxol and TP/PTX nanomicelle groups, respectively (Fig. 8c). The results of the immunohistochemical assay are shown in Fig. 8d. More apoptotic cells in the tumor were recorded in the TPH/PTX group than in all other groups, which showed no or very few apoptotic cells, further confirming the antitumor effect of TPH/PTX in resistant human lung cancer.

\section{Antitumor effects on lung metastasis in the drug-resistant breast cancer-bearing mouse models}

As shown in Fig. 8e, 4T1/ADR tumor cells were given to Balb/c mice by intravenous injection at 10 days to a drug-resistant breast cancer-bearing mouse model with lung metastasis. Number of tumor from lung metastasis were significantly showed in the 4T1/ADR tumor mice. Tumor number with TPH/PTX nanomicells treatment significantly 3.54-fold or 2.01-fold less than Taxol or TP/ PTX nanomicells. These data further support the results described above.

\section{Safety evaluation of nanomicelles in vivo}

The body weights of the animals were monitored, as shown in Fig. 8f. The body weights of mice after administration of TPH/PTX nanomicelles were not significantly different from those after administration of other formulations. There was no evidence of noticeable organ damage by H\&E staining (Fig. 8g). These results showed that TPH/PTX did not exhibit substantial cytotoxicity.

\section{Discussion}

The clinical outcomes of new drug delivery systems (DDSs) are limited by the adverse effects of conventional cancer chemotherapy. Chemotherapeutic efficacy can be significantly improved through specific delivery of anticancer drugs to the site of the tumor. Given the increasing complicated pathogenesis of cancer, bifunctional DDSs are receiving increasing attention.

Given that apoptotic resistance is observed in many types of cancer cells [29], the ability to intervene by targeting apoptotic agents to mitochondria could enable the development of new anticancer strategies. TPP, as an effective mitochondria-targeting molecule, has been used as a targeting carrier [30-32] to facilitate selective accumulation of these DDSs in mitochondria. TPP, which consists of three phenyl groups, exhibits highly lipophilic properties and delocalization of the positive charges on phosphonium in three aromatic rings. Thus, TPP was conjugated to the amphipathic PF127 through an esterification reaction to produce TPP-PF127. Preliminary studies show that Pluronic molecules not only exhibit important biological activities, such as the general properties of the block copolymer micelles mentioned above, but also restore the sensitivity of MDR tumor cells to antineoplastic agents $[19,33]$.

To prolong the blood circulation time of TPP-PF127 with positive charge nanomicelles and avoid opsonization by plasma proteins, negatively charged HA was used to modify TPP-PF127 through ester bonds to form TPH polymers, and tumor cells were targeted via CD44 receptors, which are overexpressed in many cancer cells, resulting in increased therapeutic efficacy [26]. HAase, which is widely distributed in the acidic tumor extracellular matrix and lysosomes, can easily degrade HA to achieve efficient cellular uptake, lysosomal escape and mitochondrial targeting [34].

TPH/PTX nanomicelles exhibited excellent physical properties, such as, proper particle size, high encapsulation efficiencies, and a slightly positive polydispersity index (PDI) (Table 1) enable the TPH/PTX nanomicelles to be transported into tumor tissue by the enhanced permeability retention (EPR) effect. Compared with TP/ PTX nanomicelles, the TPH/PTX nanomicelles were not very large, as observed by TEM. This result further demonstrated that the size of these nanomicelles was mainly attributed to the hydrophobic part [35]. In addition, after incubation with and without medium containing $10 \%$ FBS, the sizes of the three PTX-loaded nanomicelles were 

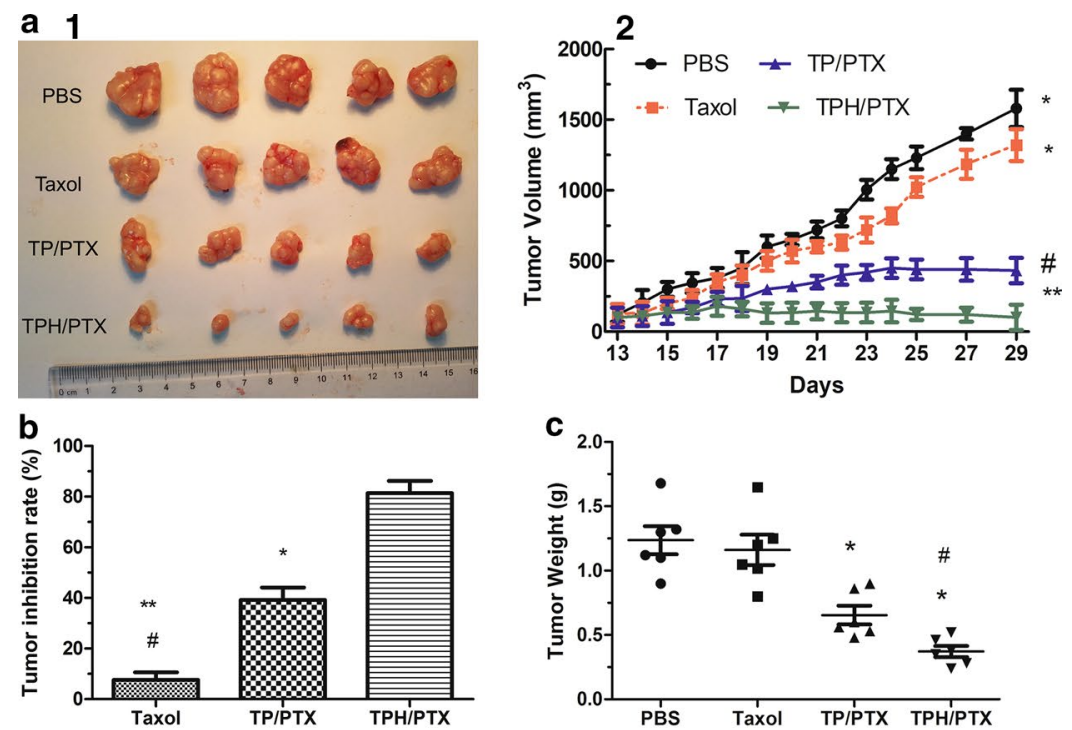

d

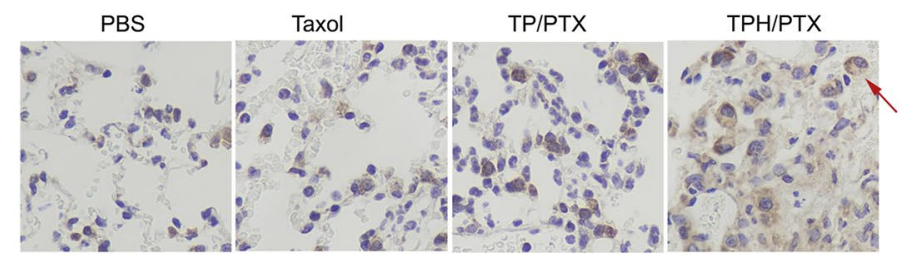

e
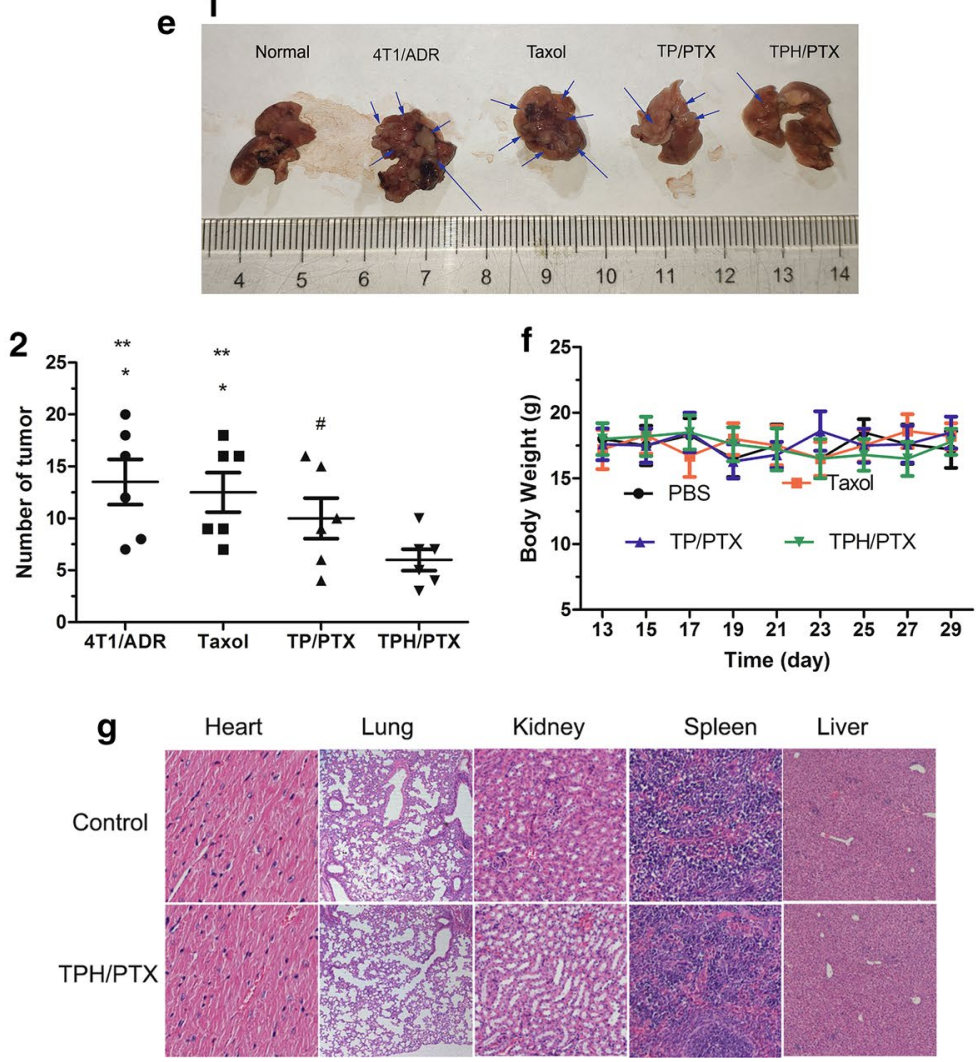
almost maintained for $25 \mathrm{~h}$, indicating the excellent stability of the three nanomicelles.

During the initial $2 \mathrm{~h}$, the delayed drug release $(<30 \%)$ would be beneficial for preventing rapid leakage during the process of delivery and would quickly increase the accumulation of the drug in the tumor masses. Due to the ester bond is $\mathrm{pH}$ sensitive [36, 37], the cumulative release of PTX from TPH/PTX at pH 4.5 is higher than those at $\mathrm{pH} 5.0$ and 7.4, indicated that in acid solid tumor tissue, the drug could be released quickly, further achieved better anti-tumor activity in vivo.

In the cytotoxicity assay, Taxol, as a free small molecular drug, entered cancer cells as easy as $\mathrm{ABC}$, thus excellent A549 cancer cells inhibition rate was observed in vitro anti-tumor activity assay. IC50 in the resistant A549/ADR with Taxol treatment, however, more 6.52-times than that in A549. TPH/PTX exhibited the strongest inhibitory effect on both A549 cells (Fig. 3a) and A549/ADR cells (Fig. 3b), compared with the other groups, and this effect was dose dependent and time dependent. The likely underlying mechanism is the rerouting of PTX to mitochondria. The results are supported by the data from the apoptosis assay.

Cells can engulf different molecules through a myriad of endocytic mechanisms [38]. Cellular uptake using various inhibitor assays showed that amiloride-treated cells internalized the TPH/C6 nanomicelles at significantly lower levels than the control cells. On the other hand, TPH/C6 nanomicelles penetrated into the cells through macropinocytosis, which was inhibited by amiloride pretreatment.

TPH/C6 nanomicelles accumulated in the acidic lysosomes after these nanomicelles entered the cancer cells, and lysosome escape of the TPH/C6 nanomicelles must occur before trafficking to mitochondria. Over $12 \mathrm{~h}$, the merged signal changed in color from faint yellow $(2 \mathrm{~h})$ to stronger yellow $(4 \mathrm{~h})$, faint yellow $(8 \mathrm{~h})$, and Kelly green $(12 \mathrm{~h})$, indicating that TPH/C6 crossed the lysosomal pathway. In A549/ADR, the color of the merged signal was not changed for free $\mathrm{C6}$, but TP/C6 and TPH/C6 showed significant changes. In particular, compared with A549, the color of the merged signal of $\mathrm{TPH} / \mathrm{C} 6$ was nearly consistent with that in A549/ADR, indicating that TPH/C6 can effectively overcome drug resistance. It is possible that $\mathrm{TPH} / \mathrm{C} 6$ nanomicelles were further degraded by HAase distributed in acidic lysosomes after internalization and that the positive charges were exposed, causing them to act as "proton sponges". Proton absorbance by buffering with positively charged TPP prevents acidification of endosomal vesicles, thereby increasing the ATPase-mediated flux of protons and counter ions, which in turn leads to osmotic swelling, endosomal membrane rupture, and eventual leakage of the nanomicelles into the cytosol, making them accessible for mitochondrial uptake [39].

After lysosome escape, mitochondrial colocalization or increased mitochondrial uptake occurred due to the positive charge of TPP on TPH/C6. The fluorescence intensity of $\mathrm{TPH} / \mathrm{C} 6$ at $12 \mathrm{~h}$ corresponds to that at $24 \mathrm{~h}$, indicating effective inhibition of multiple mitochondrial targets. The drug content in the isolated mitochondria also indicated that the internalized nanomicelles in A549 and A549/ADR cells were not attached to the surfaces of the mitochondria but were further endocytosed by mitochondria.

Depolarization of the transmembrane potential $(\Delta \psi \mathrm{m})$ is often induced by the opening of the MPTP. In addition, the loss of $\Delta \psi \mathrm{m}$ may not only result in cytochrome $\mathrm{C}$ release but also activate the apoptotic signaling pathway. In the present study, TPH/PTX significantly decreased the mitochondrial membrane potential $(\Delta \psi \mathrm{m})$, caused the release of cytochrome $C$, activated the apoptotic caspases 9/3, increased the expression of proapoptotic Bax, and inhibited the expression of antiapoptotic Bcl-2, further indicating the involvement of mitochondrial signaling pathways in subsequent apoptosis. Interestingly, the expression of caspase-3, caspase- 9 , Bax and Bcl-2 in response to TPH/PTX was nearly equal between A549 and A549/ ADR cells, suggesting that P-gp was overcome by TPH/ PTX. These results showed that the apoptosis induced by TPH/PTX was mediated by mitochondria-dependent apoptotic pathways [40] and confirmed the mitochondria-targeting effect of TPH/PTX [41].

For up to $24 \mathrm{~h}, \mathrm{TP} / \mathrm{PTX}$, and especially TPH/PTX exhibited strong fluorescence at the tumor location in vivo, indicating that HA coating prolonged the blood circulation of nanomicelles and increased the accumulation of the nanomicelles at tumoral sites via specific recognition by CD44 on cell surfaces [42, 43]. This result was further supported by ex vivo fluorescence Imaging.

Tumor volume, lung metastasis of drug-resistant breast cancer, TUNEL, and immunohistochemical assays showed that TPH/PTX exhibited the strongest tumor inhibitory effect. In summary, the following aspects can show the mechanism underlying the strong therapeutic efficacy of TPH/PTX on A549/ADR xenografts. First, $\mathrm{HA}$, as a targeted ligand, can promote the uptake of TPH/PTX nanomicelles by bypassing drug efflux. Second, TPP conjugated with PF127, which had a low HLB value, was easily internalized into tumor cells. Finally, TPP, as a mitochondria-targeted ligand, can help TP/ PTX enter mitochondria and overcome drug resistance by activating apoptosis. 


\section{Conclusions}

This study demonstrated the advantages of targeting the mitochondria of cancer cells to combat drug resistance and significantly enhanced the mitochondrial delivery of PTX through TPH/PTX nanomicelles. The specific uptake of these nanomicelles can be enhanced in drugresistant cells via CD44 molecule-mediated endocytosis and by avoiding P-gp-mediated drug efflux. This result can facilitate mitochondrial targeting of the positively charged TPP medium to overcome the drug resistance of lung cancer cells. Mitochondrial delivery as a means of "repurposing" of FDA-approved drugs currently used in the clinic appears to be a worthwhile strategy to pursue for the development of new anticancer agents.

\section{Supplementary information}

Supplementary information accompanies this paper at https://doi. org/10.1186/s12951-019-0562-3.

Additional file 1: Figure S1. Viability of A549 (a) and A549/ADR (b) cells cultured with PBS, TP, TPH, PTX-loaded nanomicelles in comparison with that of Taxol at the same PTX dose for $48 \mathrm{~h}$. All data are presented as the means \pm standard deviations $(n=3)$. ${ }^{*} P \leq 0.05$ with TPH/PTX.

\section{Abbreviations}

MDR: multiple-drug resistance; P-gp: P-glycoprotein; PF127: Pluronic F127; TPH: TPP-Pluronic F127-hyaluronic acid (HA); TP: TPP-Pluronic F127; HAase: hyaluronidase; HLB: hydrophile-lipophile balance; DCC: $N, N^{\prime}$ dicyclohexylcarbodiimide; DMAP: 4-dimethylaminopyridine; H\&E: hematoxylin and eosin; TEM: transmission electron microscopy; C6: coumarine-6; FBS: fetal bovine serum; DCM: dichloromethane; DLC: drug-loading capacity; DLE: drug-loading efficiency; ROI: region-of-interest; MOMP: mitochondrial outer membrane permeabilization; DDSs: drug delivery systems; JC1: 5, ', 6,6'tetrachloro-1,1',3,3'-tetraethylbenzimidazolylcarbocyanine iodide.

\section{Acknowledgements}

\section{Not applicable.}

\section{Authors' contributions}

$Y Z, H W, L Q, J C$ contributed equally in the design, analysis and interpretation of data for the work. FZ, HW, WS, QH, YH worked on drafting the paper. All authors read and approved the final manuscript.

\section{Funding}

This study was supported by 2018 High-level university academic backbone and training program in Guangzhou Medical University (B185004199), 2018 Guangdong Key discipline construction project of pharmacy (Q185031010), 2019 Undergraduate laboratory open project (C195015003), 2018 Construction of scientific research teaching and academic improvement project in Guangzhou Medical University (B185004025), the Scientific Research Projects of Guangzhou (No. 201707010329) and 2017 University innovation and strengthening program (Q17024031). The authors declare no conflicts of interest. We thank Prof. Chuanshan Xu (College of Pharmaceutical Science, Guangzhou Medical University, Guangzhou) for his kind assistance.

\section{Availability of data and materials}

All data generated or analyzed during this study are included in this published article (and its additional information files).

\section{Ethics approval and consent to participate}

All of the cell and animal studies were approved by Institutional Animal Care Committee and the Local Veterinary Office and Ethics Committee of Guangzhou Medical University (GZMUC 10-05010).

\section{Consent for publication}

All authors agree to be published.

\section{Competing interests}

The authors declare that they have no competing interests.

\section{Author details}

${ }^{1}$ Key Laboratory of Molecular Clinical Pharmacology \& Fifth Affiliated Hospital, Guangzhou Medical University, Guangzhou 511436, Guangdong, China.

${ }^{2}$ Center of Cancer Research, The Second Affiliated Hospital, Guangzhou Medical University, Guangzhou 510260, Guangdong, China. ${ }^{3}$ School of Pharmacy, Guangdong Pharmaceutical University, Guangzhou 510006, Guangdong, China. ${ }^{4}$ Nanfang Hospital, Southern Medical University, Guangzhou 510515, Guangdong, China.

Received: 31 October 2019 Accepted: 17 December 2019 Published online: 09 January 2020

\section{References}

1. de Groot PM, Wu CC, Carter BW, Munden RF. The epidemiology of lung cancer. Transl Lung Cancer Res. 2018;7:220-33.

2. Raez LE, Santos ES, Rolfo C, Lopes G, Barrios C, Cardona A, Mas LA, Arrieta $\mathrm{O}$, Richardet $\mathrm{E}$, Vallejos SC, et al. Challenges in facing the lung cancer epidemic and treating advanced disease in Latin America. Clin Lung Cancer. 2017;18:e71-e7979.

3. Zhou J, Zhao WY, Ma X, Ju RJ, Li XY, Li N, Sun MG, Shi JF, Zhang CX, Lu WL. The anticancer efficacy of paclitaxel liposomes modified with mitochondrial targeting conjugate in resistant lung cancer. Biomaterials. 2013:34:3626-38

4. Andre N, Braguer D, Brasseur G, Goncalves A, Lemesle-Meunier D, Guise $\mathrm{S}$, Jordan MA, Briand C. Paclitaxel induces release of cytochrome c from mitochondria isolated from human neuroblastoma cells. Cancer Res. 2000;60:5349-53.

5. Andre N, Carre M, Brasseur G, Pourroy B, Kovacic H, Briand C, Braguer D. Paclitaxel targets mitochondria upstream of caspase activation in intact human neuroblastoma cells. FEBS Lett. 2002;532:256-60.

6. Jiang $X$, Xin H, Gu J, Du F, Feng C, Xie Y, Fang X. Enhanced antitumor efficacy by $D$-glucosamine-functionalized and paclitaxel-loaded poly(ethylene glycol)-co-poly(trimethylene carbonate) polymer nanoparticles. J Pharm Sci. 2014;103:1487-96.

7. Zhang K, Jia YG, Tsai IH, Strandman S, Ren L, Hong L, Zhang G, Guan Y, Zhang Y, Zhu XX. "Bitter-Sweet" polymeric micelles formed by block copolymers from glucosamine and cholic acid. Biomacromol. 2017:18:778-86.

8. Yin J, Lang T, Cun D, Zheng Z, Huang Y, Yin Q, Yu H, Li Y. pH-sensitive nano-complexes overcome drug resistance and inhibit metastasis of breast cancer by silencing Akt expression. Theranostics. 2017;7:4204-16.

9. Strappazzon F, Cecconi F. The multifaceted mitochondrion: an attractive candidate for therapeutic strategies. Pharmacol Res. 2015:99:425-33.

10. Wang H, Gao Z, Liu X, Agarwal P, Zhao S, Conroy DW, Ji G, Yu J, Jaroniec CP, Liu Z, et al. Targeted production of reactive oxygen species in mitochondria to overcome cancer drug resistance. Nat Commun. 2018;9:562.

11. Zhitomirsky B, Farber H, Assaraf YG. LysoTracker and MitoTracker Red are transport substrates of P-glycoprotein: implications for anticancer drug design evading multidrug resistance. J Cell Mol Med. 2018;22:2131-41.

12. Korshunova GA, Shishkina AV, Skulachev MV. Design, synthesis, and some aspects of the biological activity of mitochondria-targeted antioxidants. Biochemistry. 2017;82:760-77.

13. Zielonka J, Joseph J, Sikora A, Hardy M, Ouari O, Vasquez-Vivar J, Cheng G, Lopez M, Kalyanaraman B. Mitochondria-targeted triphenylphosphonium-based compounds: syntheses, mechanisms of action, and therapeutic and diagnostic applications. Chem Rev. 2017;117:10043-12020.

14. Kazak L, Reyes A, Holt IJ. Minimizing the damage: repair pathways keep mitochondrial DNA intact. Nat Rev Mol Cell Biol. 2012;13:659-71.

15. Barreiro-Iglesias R, Alvarez-Lorenzo C, Concheiro A. Poly(acrylic acid) microgels (carbopol 934)/surfactant interactions in aqueous media. Part l: nonionic surfactants. Int J Pharm. 2003;258:165-77.

16. Saneja A, Nayak D, Srinivas M, Kumar A, Khare V, Katoch A, Goswami A Vishwakarma RA, Sawant SD, Gupta PN. Development and mechanistic 
insight into enhanced cytotoxic potential of hyaluronic acid conjugated nanoparticles in CD44 overexpressing cancer cells. Eur J Pharm Sci. 2017:97:79-91.

17. Liu R, Xiao W, Hu C, Xie R, Gao H. Theranostic size-reducible and no donor conjugated gold nanocluster fabricated hyaluronic acid nanoparticle with optimal size for combinational treatment of breast cancer and lung metastasis. J Control Release. 2018:278:127-39.

18. Park $\mathrm{H}, \mathrm{Na}$ K. Conjugation of the photosensitizer Chlorin e6 to pluronic F127 for enhanced cellular internalization for photodynamic therapy. Biomaterials. 2013;34:6992-7000.

19. Park H, Park W, Na K. Doxorubicin loaded singlet-oxygen producible polymeric micelle based on chlorine e6 conjugated pluronic F127 for overcoming drug resistance in cancer. Biomaterials. 2014;35:7963-9.

20. Moreno D, Zalba S, Navarro I. Tros de llarduya C, Garrido MJ: Pharmacodynamics of cisplatin-loaded PLGA nanoparticles administered to tumorbearing mice. Eur J Pharm Biopharm. 2010;74:265-74.

21. Mallick A, More P, Ghosh S, Chippalkatti R, Chopade BA, Lahiri M, Basu S. Dual drug conjugated nanoparticle for simultaneous targeting of mitochondria and nucleus in cancer cells. ACS Appl Mater Interfaces. 2015;7:7584-98.

22. Zheng Y, Wang W, Zhao J, Wu C, Ye C, Huang M, Wang S. Preparation of injectable temperature-sensitive chitosan-based hydrogel for combined hyperthermia and chemotherapy of colon cancer. Carbohydr Polym. 2019:222:115039.

23. Garner TP, Amgalan D, Reyna DE, Li S, Kitsis RN, Gavathiotis E. Small-molecule allosteric inhibitors of BAX. Nat Chem Biol. 2019;15:322-30.

24. Zhou Y, Wen H, Gu L, Fu J, Guo J, Du L, Zhou X, Yu X, Huang Y, Wang H. Aminoglucose-functionalized, redox-responsive polymer nanomicelles for overcoming chemoresistance in lung cancer cells. J Nanobiotechnology. 2017;15:87.

25. Kang JH, Ko YT. Enhanced subcellular trafficking of resveratrol using mitochondriotropic liposomes in cancer cells. Pharmaceutics. 2019;11:423.

26. Rios de la Rosa JM, Tirella A, Gennari A, Stratford IJ, Tirelli N. The CD44mediated uptake of hyaluronic acid-based carriers in macrophages. Adv Healthc Mater. 2017:6:1601012.

27. Yoong SL, Wong BS, Zhou QL, Chin CF, Li J, Venkatesan T, Ho HK, Yu V, Ang WH, Pastorin G. Enhanced cytotoxicity to cancer cells by mitochondriatargeting MWCNTs containing platinum(IV) prodrug of cisplatin. Biomaterials. 2014;35:748-59.

28. Brokatzky D, Dorflinger B, Haimovici A, Weber A, Kirschnek S, Vier J, Metz A, Henschel J, Steinfeldt T, Gentle IE, Hacker G. A non-death function of the mitochondrial apoptosis apparatus in immunity. EMBO J. 2019. https ://doi.org/10.15252/embj.2018100907.

29. Hanahan D, Weinberg RA. Hallmarks of cancer: the next generation. Cell. 2011;144:646-74

30. Marrache S, Pathak RK, Dhar S. Detouring of cisplatin to access mitochondrial genome for overcoming resistance. Proc Natl Acad Sci USA. 2014;111:10444-9.
31. Marrache S, Dhar S. The energy blocker inside the power house: mitochondria targeted delivery of 3-bromopyruvate. Chem Sci. 2015:6:1832-45.

32. Smith RA, Porteous CM, Gane AM, Murphy MP. Delivery of bioactive molecules to mitochondria in vivo. Proc Natl Acad Sci USA. 2003;100:5407-12.

33. Chen Y, Sha X, Zhang W, Zhong W, Fan Z, Ren Q, Chen L, Fang X. Pluronic mixed micelles overcoming methotrexate multidrug resistance: in vitro and in vivo evaluation. Int J Nanomedicine. 2013;8:1463-76.

34. Dai J, Han S, Ju F, Han M, Xu L, Zhang R, Sun Y. Preparation and evaluation of tumour microenvironment response multistage nanoparticles for epirubicin delivery and deep tumour penetration. Artif Cells Nanomed Biotechnol. 2018:46:860-73.

35. Nguyen TB, Kumar EV, Sil D, Wood SJ, Miller KA, Warshakoon HJ, Datta A, David SA. Controlling plasma protein binding: structural correlates of interactions of hydrophobic polyamine endotoxin sequestrants with human serum albumin. Mol Pharm. 2008:5:1131-7.

36. Tong R, Cheng J. Ring-opening polymerization-mediated controlled formulation of polylactide-drug nanoparticles. J Am Chem Soc. 2009;131:4744-54.

37. Sengupta S, Eavarone D, Capila I, Zhao G, Watson N, Kiziltepe T, Sasisekharan R. Temporal targeting of tumour cells and neovasculature with a nanoscale delivery system. Nature. 2005;436:568-72.

38. Doherty GJ, McMahon HT. Mechanisms of endocytosis. Annu Rev Biochem. 2009;78:857-902.

39. Albrecht J, Sonnewald U, Waagepetersen HS, Schousboe A. Glutamine in the central nervous system: function and dysfunction. Front Biosci. 2007:12:332-43.

40. Turillazzi E, Cerretani D, Cantatore S, Fiaschi Al, Frati P, Micheli L, Neri M, Cipolloni L, Di Paolo M, Pinchi E, et al. Myocardial oxidative damage is induced by cardiac Fas-dependent and mitochondria-dependent apoptotic pathways in human cocaine-related overdose. Sci Rep. 2017;7:44262

41. Chou WH, Liu KL, Shih YL, Chuang YY, Chou J, Lu HF, Jair HW, Lee MZ, Au MK, Chung JG. Ouabain induces apoptotic cell death through caspaseand mitochondria-dependent pathways in human osteosarcoma U-2 OS cells. Anticancer Res. 2018;38:169-78.

42. Shi S, Zhou M, Li X, Hu M, Li C, Li M, Sheng F, Li Z, Wu G, Luo M, et al. Synergistic active targeting of dually integrin alphavbeta3/CD44-targeted nanoparticles to B16F10 tumors located at different sites of mouse bodies. J Control Release. 2016;235:1-13.

43. Lu CH, Lin CH, Li KJ, Shen CY, Wu CH, Kuo YM, Lin TS, Yu CL, Hsieh SC. Intermediate molecular mass hyaluronan and $\mathrm{CD} 44$ receptor interactions enhance neutrophil phagocytosis and IL-8 production via p38- and ERK1/2-MAPK signalling pathways. Inflammation. 2017:40:1782-93.

\section{Publisher's Note}

Springer Nature remains neutral with regard to jurisdictional claims in published maps and institutional affiliations.
Ready to submit your research? Choose BMC and benefit from:

- fast, convenient online submission

- thorough peer review by experienced researchers in your field

- rapid publication on acceptance

- support for research data, including large and complex data types

- gold Open Access which fosters wider collaboration and increased citations

- maximum visibility for your research: over $100 \mathrm{M}$ website views per year

At BMC, research is always in progress.

Learn more biomedcentral.com/submissions 